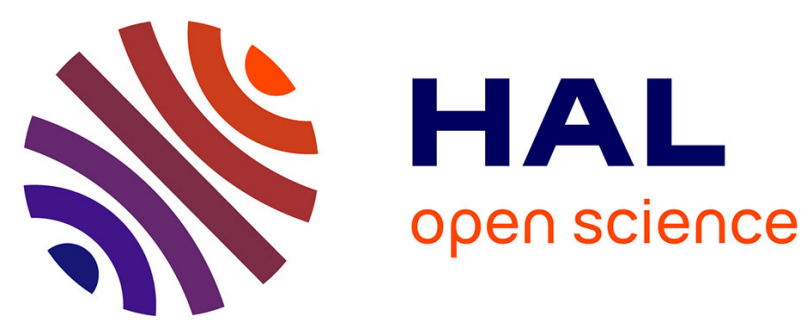

\title{
Quantitative risk assessment in the early stages of a CO2 geological storage project: implementation of a practical approach in an uncertain context
}

Louis de Lary de Latour, Jean-Charles Manceau, Annick Loschetter, Jeremy Rohmer, Olivier Bouc, Isaline Gravaud, Christophe Chiaberge, Pierre Willaume, Thierry Yalamas

\section{To cite this version:}

Louis de Lary de Latour, Jean-Charles Manceau, Annick Loschetter, Jeremy Rohmer, Olivier Bouc, et al.. Quantitative risk assessment in the early stages of a $\mathrm{CO} 2$ geological storage project: implementation of a practical approach in an uncertain context. Greenhouse Gases: Science and Technology, 2015, 5 (1), pp.50-63. 10.1002/ghg.1447 . hal-01118607

\section{HAL Id: hal-01118607 https: / hal-brgm.archives-ouvertes.fr/hal-01118607}

Submitted on 19 Feb 2015

HAL is a multi-disciplinary open access archive for the deposit and dissemination of scientific research documents, whether they are published or not. The documents may come from teaching and research institutions in France or abroad, or from public or private research centers.
L'archive ouverte pluridisciplinaire HAL, est destinée au dépôt et à la diffusion de documents scientifiques de niveau recherche, publiés ou non, émanant des établissements d'enseignement et de recherche français ou étrangers, des laboratoires publics ou privés. 


\section{Quantitative risk assessment in the early stages of a}

\section{$2 \mathrm{CO}_{2}$ geological storage project: implementationof a}

3 practical approach in an uncertain context.

4

5

6

7

8

9

Louis de Lary ${ }^{a}$, Jean-Charles Manceau ${ }^{a}$, Annick Loschetter ${ }^{a}$, Jeremy Rohmer ${ }^{a}$, Olivier Bouc ${ }^{a}$, Isaline

Gravaud $^{a}$, Christophe Chiaberge ${ }^{a}$, Pierre Willaume ${ }^{b}$, ThierryYalamas ${ }^{b}$

${ }^{a}$ BRGM, 3 av. C. Guillemin BP36009, F-45060 Orléans Cedex 2, France

${ }^{b}$ PHIMECA, 18/20 Boulevard de Reuilly, 75012 Paris, France

Keywords: risk assessment, $\mathrm{CO}_{2}$ storage, uncertainty analysis, quantification

Corresponding author:

E-mail address: I.delarydelatour@brgm.fr (L. de Lary)

Tel.: (+33) 2386446 24; fax: (+33) 238643689

\section{Abstract}

Methodologies for quantitative risk assessment regarding $\mathrm{CO}_{2}$ storage operations are currently scarce mostly because of the lack of experience in this field and the relatively significant uncertainty degree regarding the subsurface intrinsic properties and the processes occurring after the injection starts. This paper presents a practical approach designed to perform a quantitative risk assessment in an uncertain context. Our approach is illustratedon a realistic case study (Paris basin, France), conceived to be representative of the level of information available in the early stages of a project.It follows the risk assessment principles from the international standard(ISO 31000:2009), whichare adapted to account for the specificities and challenges of subsurface operations. After the establishment of the context of the specific case study, the main risks were identified and we analysed two different risk scenarios(risk of brine 
26 leakage from an abandoned well, riskof subsurface use conflict). These scenarios were selected to give a comprehensive overview of different types of analysis in terms of available data, modelling tools and uncertainty management methodologies. The main benefit of this paper is to proposeanapproach, based on existing risk assessment standards, best practices and analysis tools, which allows an objective quantitative risk analysis taking into account the uncertainties, and therefore enablesa fully informed decision-making whileevaluating risk acceptability. 


\section{Introduction}

The aim of Carbon dioxide Capture and Storage (CCS) is to contribute to the limitation ofanthropogenic $\mathrm{CO}_{2}$ release inthe atmosphere by capturing $\mathrm{CO}_{2}$ and storing it permanently in appropriate deep (usually $>800 \mathrm{~m}$ ) geological formationsamong which saline aquifers are seen to provide the best world-wide geographical distribution and storage capacity. ${ }^{1}$ As for any industrial activity, the development of environmentally and healthy safe CCS must rely on robust risk assessment and management on the short as well as on the long term period to comply with regulatory frameworks, such as the CCS Directive in the European Union (Directive 2009/31/EC). ${ }^{2}$

Risk management, as standardized by ISO $31000: 2009,{ }^{3}$ is a continuous and iterative loop thatcomprises the following processes: 1) establishment of the contextdefining the objectives of the risk management, the input parameters/data and the risk criteria used to evaluate the significance of risks, 2)risk assessmentthat consistsin theidentification, analysisand evaluation of risks, 3)risk treatmentthat aims at reducing the level of risk, 4)communication with internal and external stakeholders and 5) monitoringand review of the risk management process. This paper focuses on risk assessment. The specific purpose of this step, regarding the ISO31000:2009 standard is to supply information on different risks in order to allow an informed decision-making regarding the level of risk and to decide whether the different risks need to be treated. Basically, during risk assessment, the risks potentially relevant are selected (risk identification), then their consequences on vulnerable elements and their likelihood are further studied(risk analysis). The risks acceptability and the necessity for treatment are finally evaluated (risk evaluation).

Risk assessment is particularly novel for the geological storage part of CCS, compared to the surface facilities and activities (capture and transport)for which more classical industrial safety practices apply. Up to now, the $\mathrm{CO}_{2}$ geological storage experience is limited and only 
six sites are currently in operation or at an advanced stageworldwide ${ }^{1}$. Some experience can be gained from other underground operations; but the specificities of each activity regarding the risks they induce make difficult the direct transposition of the methodologies and tools to deal with them. ${ }^{4}$ Enhanced oil recovery, consisting of injecting $\mathrm{CO}_{2}$ to recover a larger quantity of oil does not have the same primary purpose of $\mathrm{CO}_{2}$ confinement as CCS. Natural gas seasonal storage, even though it could focus on similar geological formations, is different in terms of injected fluid and associated interactions with native fluids and formations, and in terms of storage time scale ( 1 to few years for natural gas storage vs. at least centuries for $\mathrm{CO}_{2}$ storage). The different context and processesare also a reason why the analogy between carbon storage and nuclear waste storage should be done only with care. The lack of experience can make difficult the risk identificationbecause new risks need to be considered. Besides, the consequence and likelihood analysisrequires new tools and new risk criteriahave to be set to enable the risk evaluation.

In addition to the lack of experience, risk assessment is particularly challenging forCO $\mathrm{CO}_{2}$ geological storagebecause safety significantly relies on the natural properties of the geological storage complex and their evolution over long term time scale. In contrast with common industrial risks where the engineered components of installations are well known because they are the result of construction of human being and because of experience, the geological reservoirs and associated features properties are:1) inherently variable (aleatory uncertainty) and 2) our knowledge of these objects is always incomplete and imprecise (epistemic uncertainty) ${ }^{4,5} \mathrm{CO}_{2}$ storage projects therefore face a high degree of uncertainty, especially in their early stages because the knowledge of the site is limited.

Furthermore, understanding and representing the phenomena occurring with the injection of $\mathrm{CO}_{2}$ is also complex. The behaviour of a storage site is a combination of multiple processes multiphase flow, mechanical, geochemical, thermal, biological - , occurring at different ${ }^{1}$ http://www.globalccsinstitute.com/projects/browse, accessed April 1, 2014 
spacescales- pore-scale, rock sample, near well bore, reservoir, regional - and time scales from several years to a few centuries - , and potentially coupled.These phenomena may not be perfectly known and even if they are,assumptions are usually made during the models construction.

Consideringnotably these elements and the nature of geological risks, suggested approaches to assess risks related to $\mathrm{CO}_{2}$ storage are mostly considered as qualitative orsemi-quantitative and few could beconsidered as quantitative. ${ }^{6-9,}{ }^{34}$ The boundaries between methods are often quite difficult to draw. From the ISO 31010:2009 standard, ${ }^{10}$ qualitative assessment uses qualitative scale (such as "high", "medium" and "low") to define consequences, probability and the level of risk. Semi-quantitative methods use numerical scales to assess the level of consequence and probability and use a formula to deduce the values for the level of risk. Quantitative assessment estimates values for the consequences and the associated probabilities and gives values for the level of risk.Among existing approaches, uncertainties on parameters are often not taken into account explicitly and the distinction between the two facets (aleatory and epistemic) is rarely considered.

The objective of this paper is to propose an approach for preliminary quantitative risk assessment and risk treatment decision support adapted to the constraints explained above and based on the international standards on risk management (ISO 31000:2009). By preliminary, we mean that this approach is adapted to the early stages of a project, when the site has been selected but before the beginning of the injection operations. The approaches dedicated to the risk assessment update, notably using monitoring data over time, aretherefore out of the scope of this paper. This preliminary study is characterized by a relatively high level of uncertainties regarding the knowledge of the site, which gives rise to uncertainties onthe predictions of the storage evolution. In this paper, the approach we suggest is implemented on a realistic case 
study (Paris basin, France), conceived to be representative of the level of information available in the early stages of a project.

The remainder of this paper followsthe different steps achieved for this implementation, in accordance withthe ISO 31000:2009 workflow and terminology for risk assessment: first, the case study and the data available are described (section2, establishment of the context), then we explain how the risks were identified and the scenarios to analysewere deduced (section 3, risk identification). In section 4 (risk analysis)we focus the assessment on two scenarios in order to quantify the risks accounting for the uncertain context. These two scenarios were selected to give a representativeoverview of different types of analysis in terms of data available, modelling tools and uncertainty management methodologies. The purpose of presenting the analysis of these two scenarios is to illustrate the approach we propose; the results of modelling are entirely secondary. Finally, in section 5 (risk evaluation) we provideelements to perform the evaluation of the risks acceptability. In each section, we describe the method and then the results obtained on the case study. In the end, the application of these steps shows how the challenges linked with $\mathrm{CO}_{2}$ geological storage could be accountedto perform a quantitative risk assessment of these operations and to provide objective and scientific elements to the stakeholders for decision-making regarding risk management.

\section{Establishment of the context}

The establishment of the context requires the definition of the objective and the scope of the risk management.The objective is here to assess the risks for the existing vulnerable elementsduring the operations and the short term monitoring phase between the injection stopping and the transfer of responsibility to the competent authority $>20$ years according to the European Directive on $\mathrm{CO}_{2}$ storage). ${ }^{2}$ Long term assessment is excluded from the study. 
Another key aspect of the establishment of the context is the gathering of existing data and associated uncertainties necessary for the assessment, which comprises the geological media (geological, hydrogeological andpetrophysical properties), the planned operations (rate, duration)and the existing vulnerable elements (populated areas, aquifers, sensitive areas at ground level, other activities).

The case studies chosen in this paper have been the subject of previous works and have been designed as an area with a good $\mathrm{CO}_{2}$ storage potential. ${ }^{11,12} \mathrm{No} \mathrm{CO}_{2}$ storage has been performed nor actually planned in this region, but these previous studies provide enough raw data to consider this site as a realistic case study. The considered area is located in the Paris Basin, which is the largest onshore sedimentary basin in France covering a large surface $\left(110,000 \mathrm{~km}^{2}\right)$ in the North of France. ${ }^{13}$ The central part of the Basin is filled with about $3000 \mathrm{~m}$ of sediments.

The methodology used for the storage formation and injection point selection in previous studies was based on a screening phase that integrated the geological, environmental and legal constraints. ${ }^{14}$ Decision was supported by a Geographical Information System (GIS) compiling the data about geology, other subsurface activities, faults, deep wells, deep aquifers, density of population, sensitive ecological areas, seismic hazard and industrial activities, thus enabling the delimitation of exclusion zones using criteria related to risks, costs, operation and conflicts of interests. The selected saline aquifer is the lower Triassic (Keuper) sandstone 


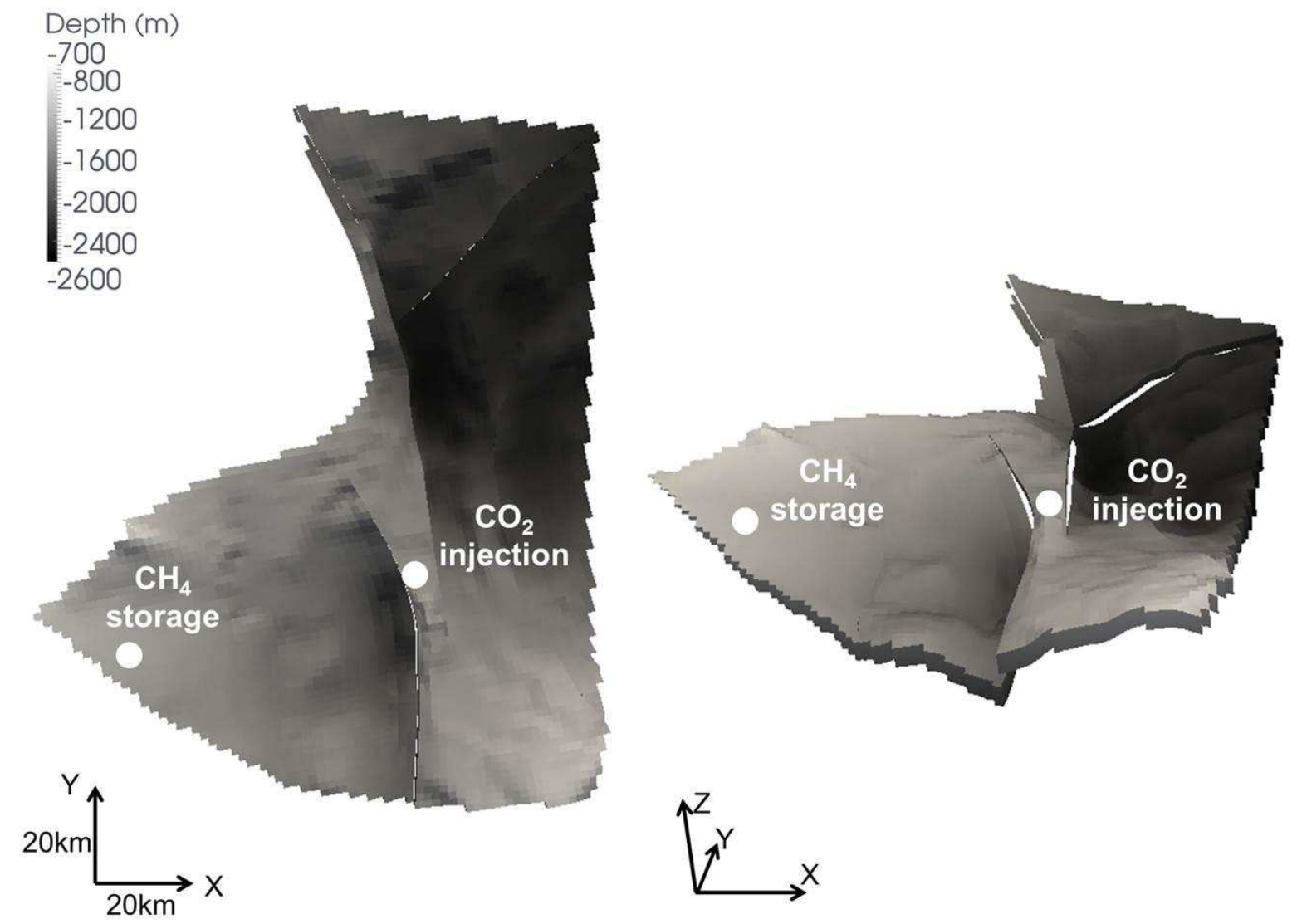

Figure 3), the formation is ca. $60 \mathrm{~m}$ thick and ca. $1600 \mathrm{~m}$ deep.Two major faults are located near the chosen injection point. In the Paris basin, plugged wells are considered as well localized. However, for some of them, very littleinformation is available about their characteristics.Regarding the operations, the fictitious injection characteristics were taken as equal tothose accounted in the previous studies: ${ }^{14}$ the injection rate is about $2 \mathrm{MtCO}_{2} /$ year during 30 years.

The Albian aquifer locatedabout $1000 \mathrm{~m}$ above the target reservoir is among the main vulnerable elements of the region. ${ }^{15}$ Due to the geological confinement this aquifer is naturally protected from any sort of pollution from the soil surface and it has drinking water quality.This resource is thus reserved mainly for emergency supply of the Paris region in case of pollution of other sources or for the supply of some industrial activities requiring high and constant water quality. The other underground activities targeting the lower Triassic aquifer 
166 level, the existing stakes, in this low density population area, are mainly some sensitive 167 ecological areas, and activities such as agriculture or forestry.

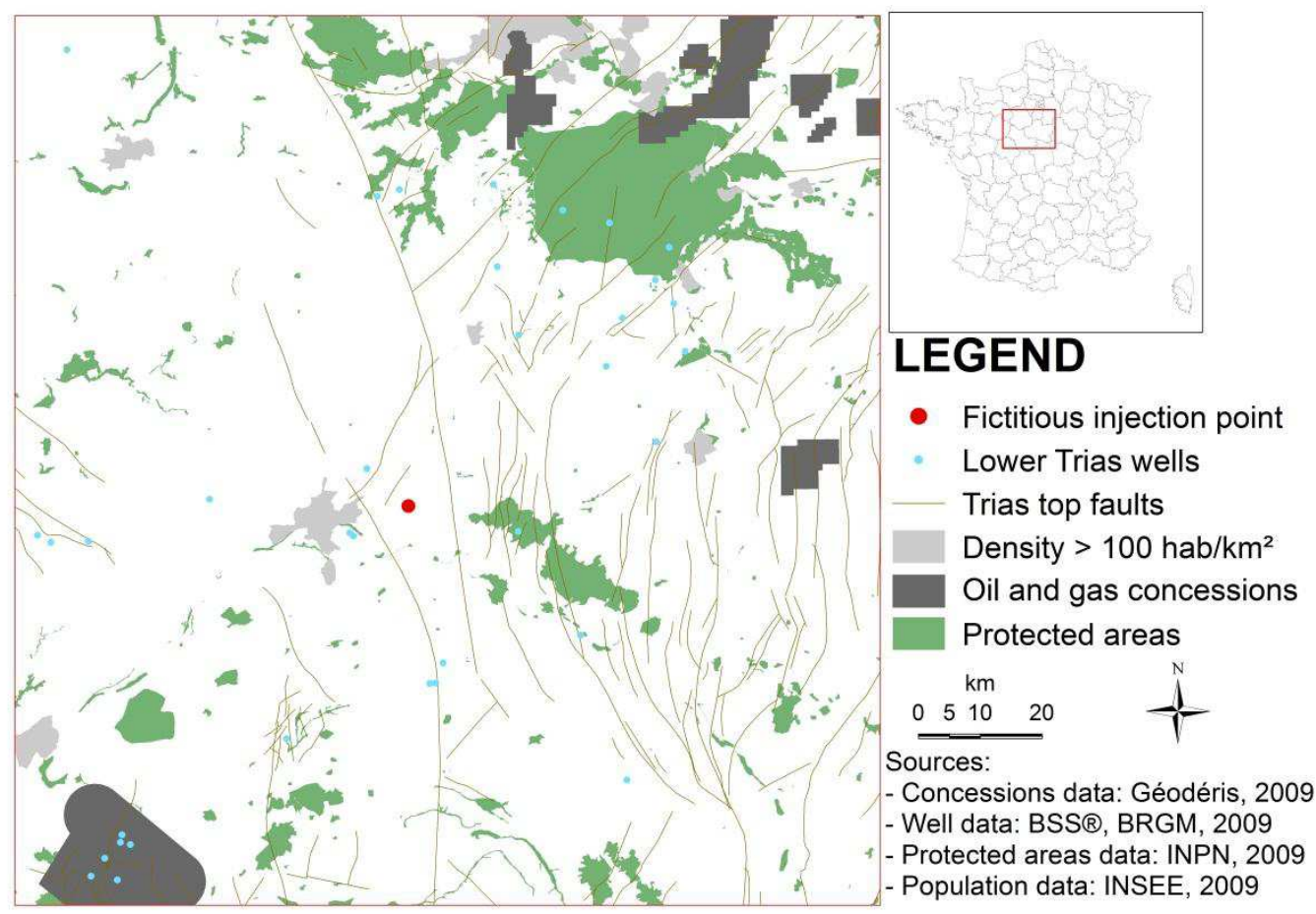

Figure 2 recaps the key elements highlighted in the establishment of the context. 


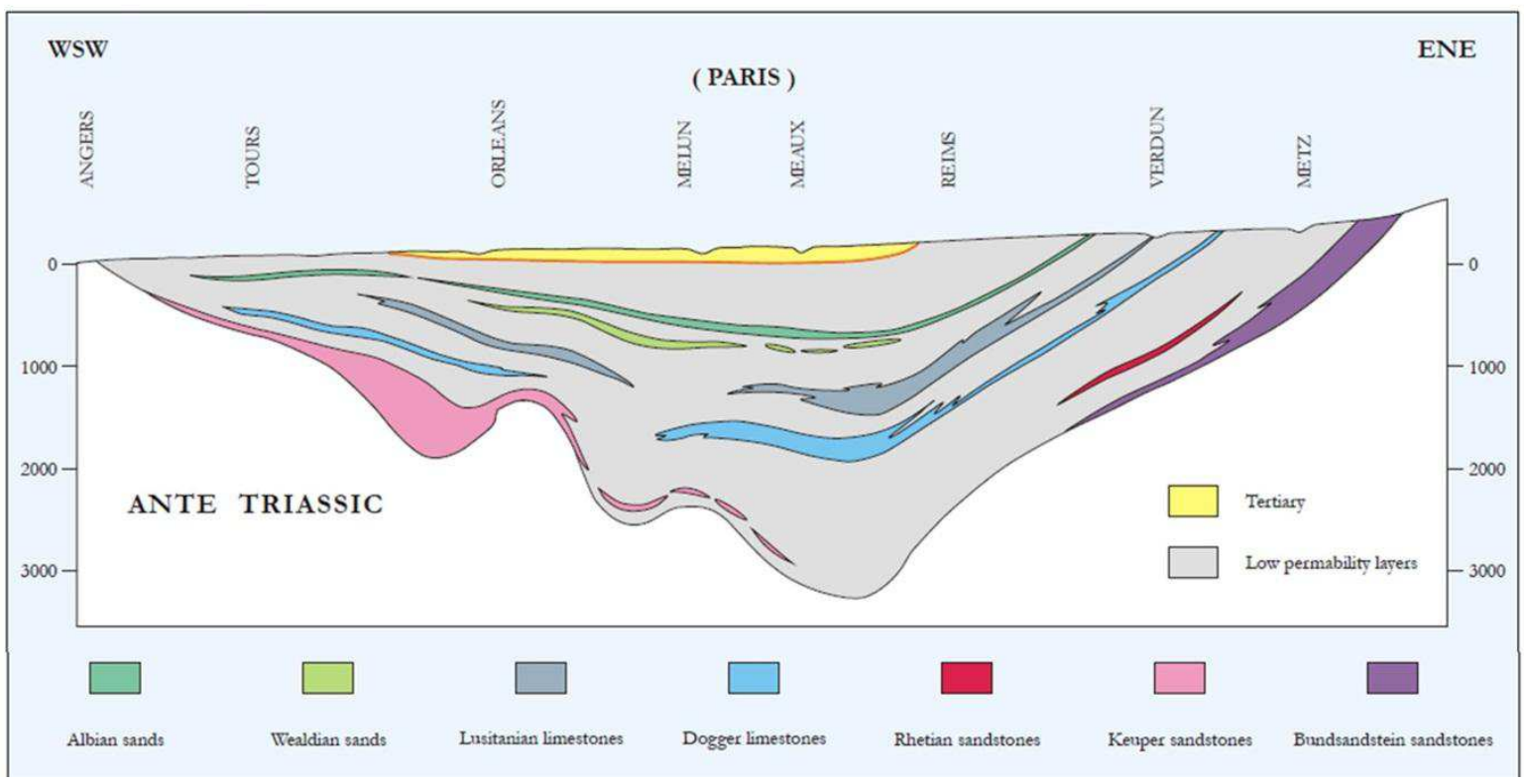

Figure 1: Schematic cross-section of the main aquifer units on a WSW-ENE transect of the Paris basin (adapted from ${ }^{12,16}$ ).

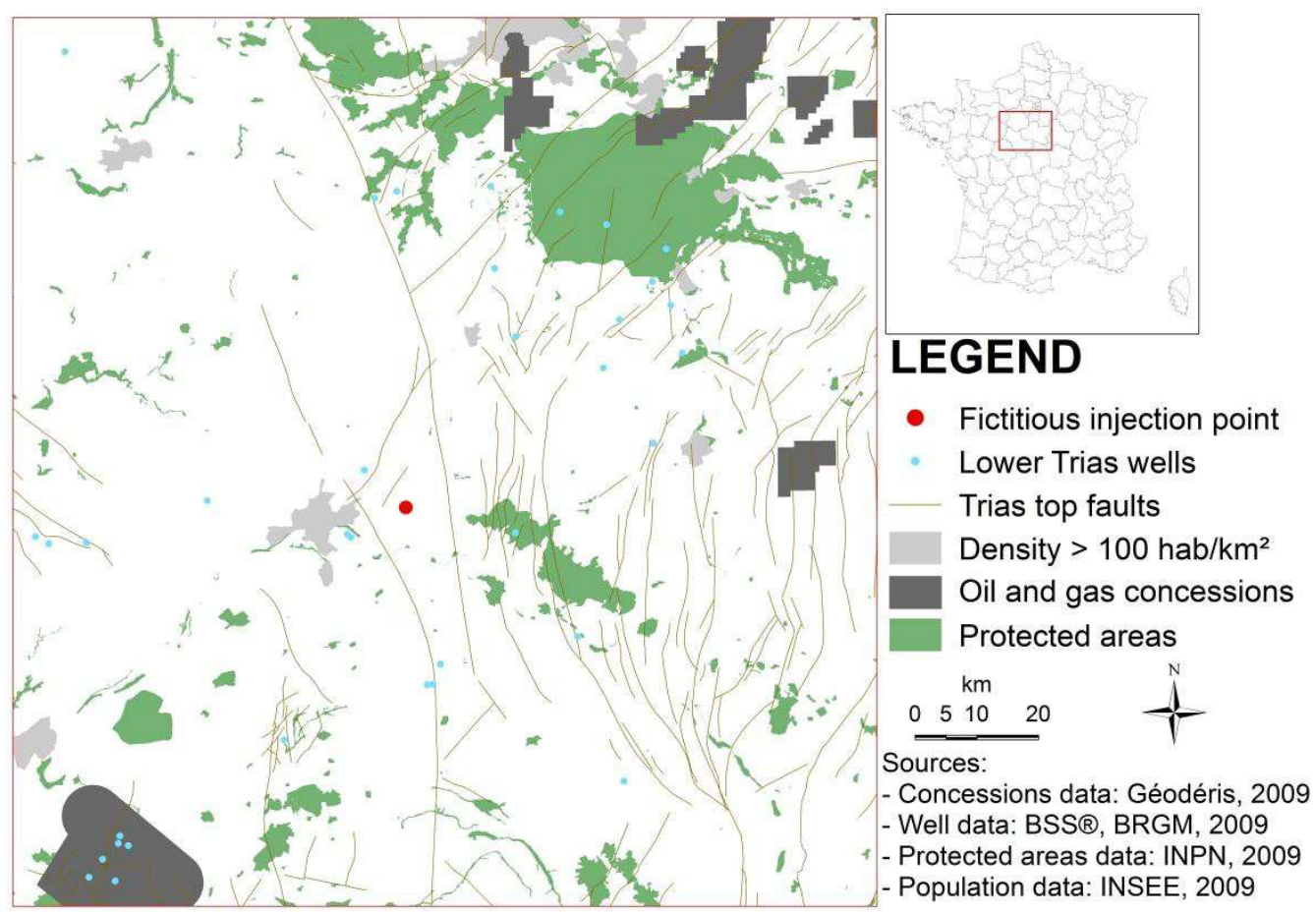

Figure 2 : Position of the fictitious injection well, faults, wells, other underground exploitations and protected areas in the studied area. 


\section{Risk identification}

By definition, risk identification is a systematic inventory and description of risks and of their causes and consequences. Numerous approaches have been developed in many fields; we adopt in this study a systematic team approach,where a panelof experts with different skills is guided through a systematic process and identifies the risks specific to the injection project from a predefined set of risks scenarios. Rather similar approaches have been proposed by several authors. ${ }^{6,17,18}$ For the expert team work, bow-tie trees (or diagrams) were used as a supporting tool. They are a graphical representation of the risk events together with their initiating events, the outcome events until the potential impact they can lead to. Each path from an initiating event to an impact event is called a risk scenario.Two different steps were necessary, 1) the elaboration of generic bow-tie trees, and 2) the risk identification consisting in the selection and adaptation of the relevant scenarios to the chosen site.

The elaboration of generic trees for $\mathrm{CO}_{2}$ storage in saline aquifers was based on a list of main risk events and a list of impactsfrom Bouc et al. ${ }^{19}$.The diagrams were established by a panel of experts in the following fields: risk management, $\mathrm{CO}_{2}$ storage, geology, hydrogeology, multiphase flow, reservoirs, geomechanics, geochemistry, numerical simulation of subsurface phenomenon, wells, and impacts in the field of CCS. Starting from each of the main events, the experts panel was asked to determine iteratively all the possible causes (bottom-up approach) up toprimary causes and all the possible consequences (top-down approach)down tothe impacts. In order to check that all the possible primary causes were considered exhaustively, an analysis of failure inspired from the FMEA (Failure Modes and Effects Analysis)was carried out. Results were synthetized on several bow-tie treesseparated between the events occurring near the wellbores and those concerning more generallythe geological medium. Two main phases were distinguished: operational phase and post operation. 
Diagrams were designed with the finestlevel of details in order to be used as a basis for 202 identification at any step of a project.

The risk identification on the specific case study of this paper implies the adaptation of the generic bow-tie trees to the chosen site, and the selection of relevant risk scenarios to be further analysed.Based on the generic diagrams from step 1, anothergroup of experts (with specific knowledge on the case study in addition to similar skills as the above-mentioned group)systematically discussed all the events of each tree. Those considered unrealistic or impossible due to the sitecondition were removed from the trees. Among the remaining events, the experts were asked to discuss the priority of analysis for the events leading to the same consequence.A simplification of the generic diagrams was sometimes necessary 211 whenthe details level of the diagrams was considered too important regarding the objective of our study (preliminary quantitative risk assessment). This approach resultedin fine in a wide number of possible scenariosdue to numerous possible combinations of causes,main events and consequences.Therefore, the final step of the identification was to buildfrom all the scenarios a representative list of conservativescenarios. The conservative scenarioswere defined as the scenarios that should represent an upper bound of the risk level. They were established from the discussions on the priority on each event and doing conservative hypotheses. The main purpose of this last step was to end-up the identification process with a manageable number of scenarios to analyse.

Applying this approach on the potential $\mathrm{CO}_{2}$ storage site, the work of the expertspanel resulted in the following conservative scenarios to be analysed:

1- Flow modification in the $\mathrm{CO}_{2}$ storage geological formation and subsequent potential (pressure) impacts on others subsurface activities;

2- Native fluid migration through abandoned wells and potential impacts on overlying aquifers quality; 
3- Loss of mechanical integrityin the reservoir leading potentially to induced seismicity on other subsurface structures (on wells notably);

4- Loss of mechanical integrity of the caprock leading potentially to migration risk scenarios;

5- Fluid (native or injected) migration through the caprock (higher permeability areas or fractures/faults) with potential impacts on overlying aquifers.

A comprehensive risk analysis should focus on the fivescenarios. Only the analyses of scenarios1and 2are presented in this paper. These two risk scenarioswere chosen to provide a representativeoverview on the different types of analysis that could be performed, with different choices in terms of quantification (modelling) tools and uncertainty management methodologies.

\section{Risk analysis}

\subsection{Scenario 1: Flow modification in the storage formation and potential} pressure impacts on others subsurface activities

\subsubsection{Presentation of the scenario and choices for risks quantification}

During the experts workshops, it was decided that the potential impacts of theover pressurizationof the $\mathrm{CO}_{2}$ storage on the subsurface activities targeting the sameaquifer formation (oil concessions and gas storage operations) should be further analysed and quantified. In this paper, we propose to consider afictitiousseasonal gas storage field that would be located in the close surrounding of the contemplated injection point (ca. $60 \mathrm{~km}$ 


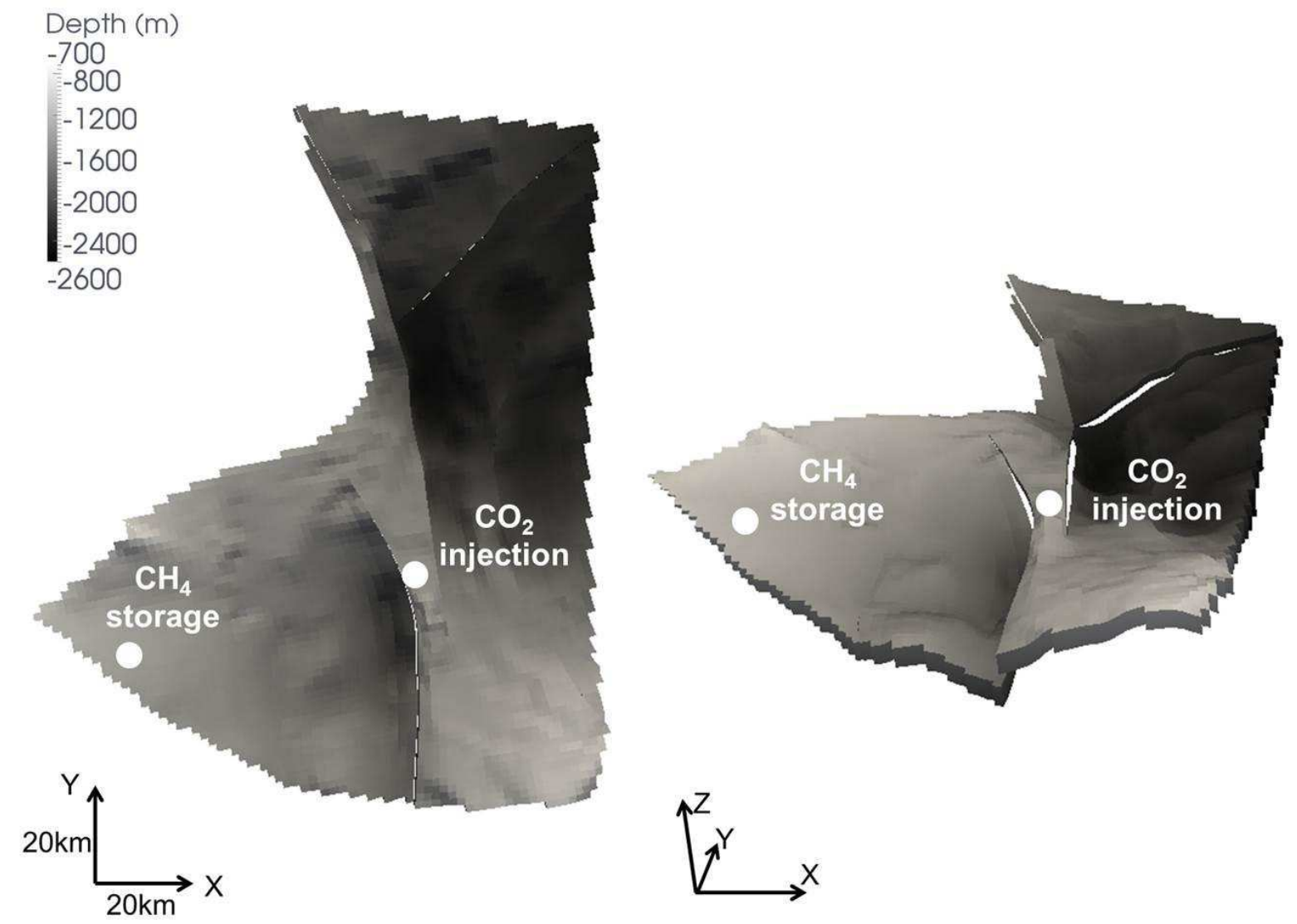

Figure 3). We consider that in this storage field ca. $0.4 \mathrm{Mt}$ of gas $\left(\mathrm{CH}_{4}\right)$ is injected each summer and the same amount is withdrawn during each winter. Simulations were run for 30 years after 6 years of reservoir filling designed to set up the cushion gas (i.e. the amount of gas that remains permanently in the aquifer to allow the storage operations).

For the quantification of the pressure impacts of the $\mathrm{CO}_{2}$ injection on the natural gas storage operations, large-scale numerical 3D flow modelling was conducted. A geological model of the formation was built using Petrel@. The dynamic modelling simulations were performed with the multiphase flow transport simulator TOUGH2 combined with its module EOS7C accounting for the properties of $\mathrm{CO}_{2}-\mathrm{CH}_{4}$-brine mixture. ${ }^{20,21}$ The final model is made of 


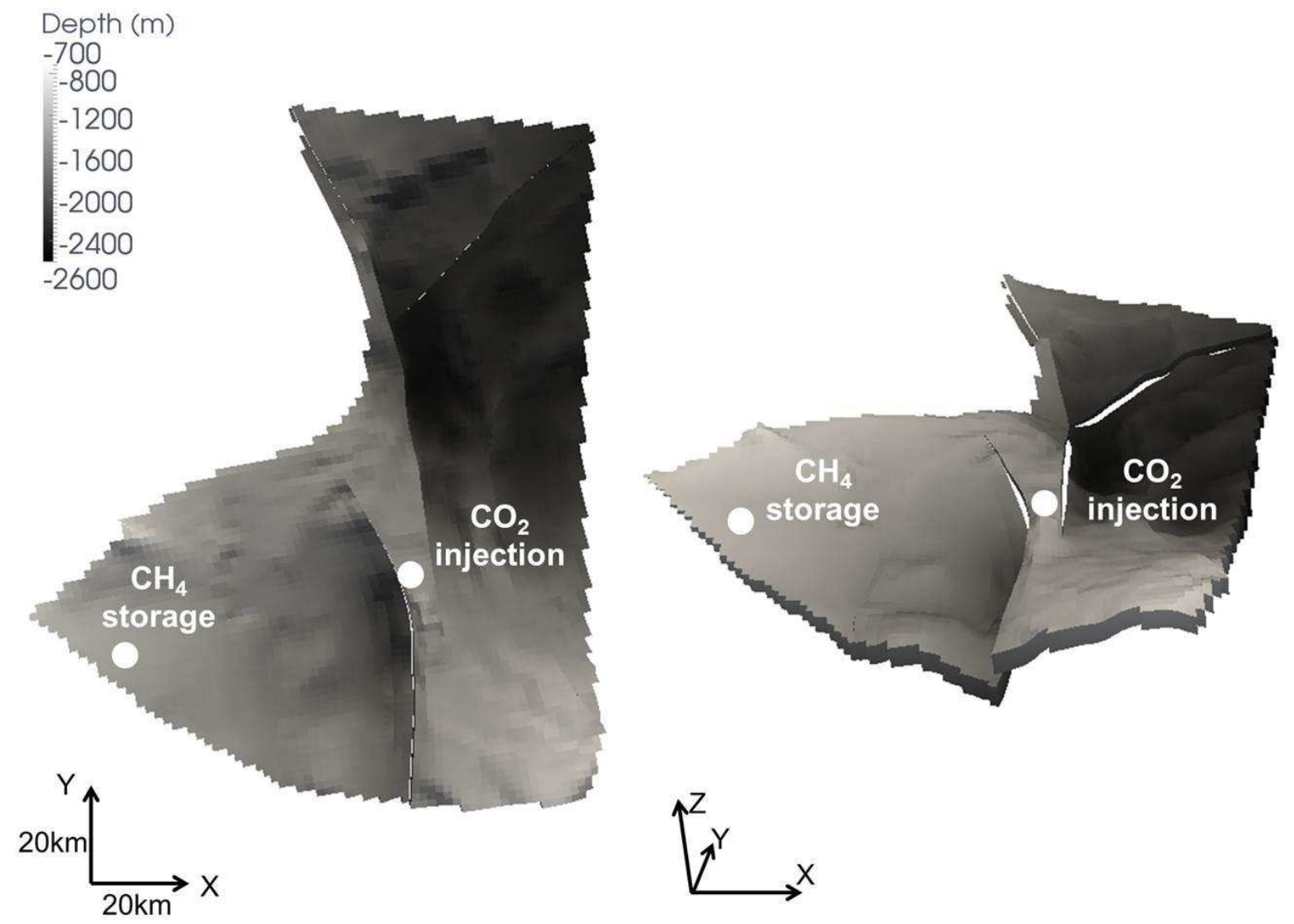

Figure 3. The natural gas storage and $\mathrm{CO}_{2}$ injection operationswere simulated by constant $\mathrm{CH}_{4}$ injection/extraction rate $(0.4 \mathrm{Mt} / \mathrm{y}$ injected and extracted during 30 years $)$ and $\mathrm{CO}_{2}$ injection rate $\left(2 \mathrm{Mt} / \mathrm{y}\right.$ during 30 years). The pressure impact on the $\mathrm{CH}_{4}$ storage caused by the $\mathrm{CO}_{2}$ injection operations was assessed through the overpressure induced by the $\mathrm{CO}_{2}$ storage operations in comparison with the $\mathrm{CH}_{4}$ storage-only situation. As indicators of this pressure impact, we chose:

- Indicator 1: the average relative overpressure (in \%) due to the $\mathrm{CO}_{2}$ injection within the 5 bars pressure footprint of the $\mathrm{CH}_{4}$ storage;

- Indicator 2: the average relative overpressure (in \%) due to the $\mathrm{CO}_{2}$ injection within the 1 bar pressure footprint of the $\mathrm{CH}_{4}$ storage. 


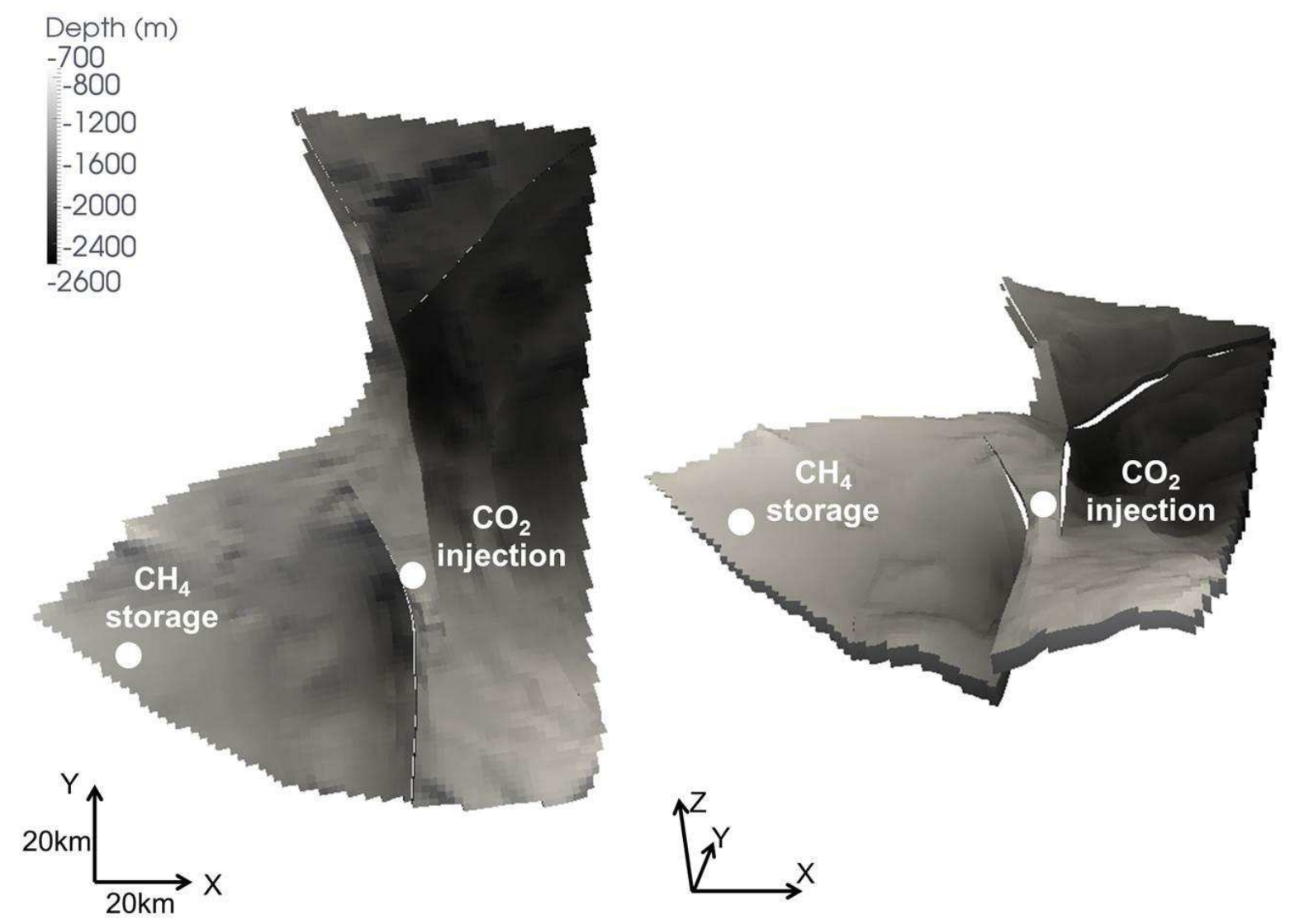

Figure 3: Twoviews (2D top view on the left, 3D perspective view on the right) of the static model of the geological formation of interest used in the flow simulationsfor scenario 1 quantification - the vertical scale is exaggerated in the perspective view

\subsubsection{Representation of available information}

A probability distribution for porosity and permeabilitywas established from the available data set at several wells reaching the formation (the spatial variability of porosity and permeability was however not considered in the simulations). Due to the lack of data, expert knowledge elicitationwas used to determine a probability distribution for the pore compressibility (pore compressibility is the fractional change of pore volume of rock with a unit change in internal pressure). Themultiphase flow parameters (relative permeability and capillary pressure)both for the $\mathrm{CO}_{2}$ /brine $\mathrm{CH}_{4}$ /brine systems in sandstones are more difficult to characterize and generally few data can be found in the literature. Theywere thus considered fixedin this study. The choices made for the main uncertain input parameters are summarised in Table 1. 
Table 1: Uncertain input parameters considered for scenario 1 simulation.

\begin{tabular}{|c|c|c|c|}
\hline Parameters & Source of information & $\begin{array}{l}\text { Representation } \\
\text { mode }\end{array}$ & Values \\
\hline Porosity (-) & $\begin{array}{l}\text { Measurements } \text { (after } \\
\text { Martin }(2009)^{33}\end{array}$ & $\begin{array}{l}\text { Probabilistic } \\
\text { distribution }\end{array}$ & $\begin{array}{l}\text { Normal distribution (mean: } \\
0.165 \text {; standard deviation: } \\
0.053)\end{array}$ \\
\hline Permeability $\left(\mathrm{m}^{2}\right)$ & $\begin{array}{l}\text { Measurements (after } \\
\text { Martin }(2009)^{33}\end{array}$ & $\begin{array}{l}\text { Probabilistic } \\
\text { distribution }\end{array}$ & $\begin{array}{l}\text { Log-normal distribution (mean: - } \\
28.4 \text {; standard deviation: } 0.9 \text { ) }\end{array}$ \\
\hline $\begin{array}{l}\text { Pore compressibility } \\
\left(\mathrm{Pa}^{-1}\right)\end{array}$ & Expert opinion & $\begin{array}{l}\text { Probabilistic } \\
\text { distribution }\end{array}$ & $\begin{array}{l}\text { Uniform law (support: } \\
1.10^{-10}-9.10^{-10} \text { ) }\end{array}$ \\
\hline
\end{tabular}

\subsubsection{Uncertainty propagation}

A Monte-Carlo approach was chosen to analyse the effects of parameter uncertainties on the outcomes of the flow modelling. Given the number of parameters, 10,000 simulations would be necessary for this analysis. This large number of direct simulations was not feasible in practice since the simulator used for this study is computationally intensive (up to one day for one simulation). A metamodel(a surface response) was thus developed from the physical model and the Monte Carlo simulationswere performed on this analytical model. The model approximation was built from100 simulations with the physical model and using polynomial chaos expansion. ${ }^{22}$ It was validated through a cross-validation procedure. The Monte Carlo 
analysis with the metamodelwas achieved using the Open Turns tool ${ }^{2}$.
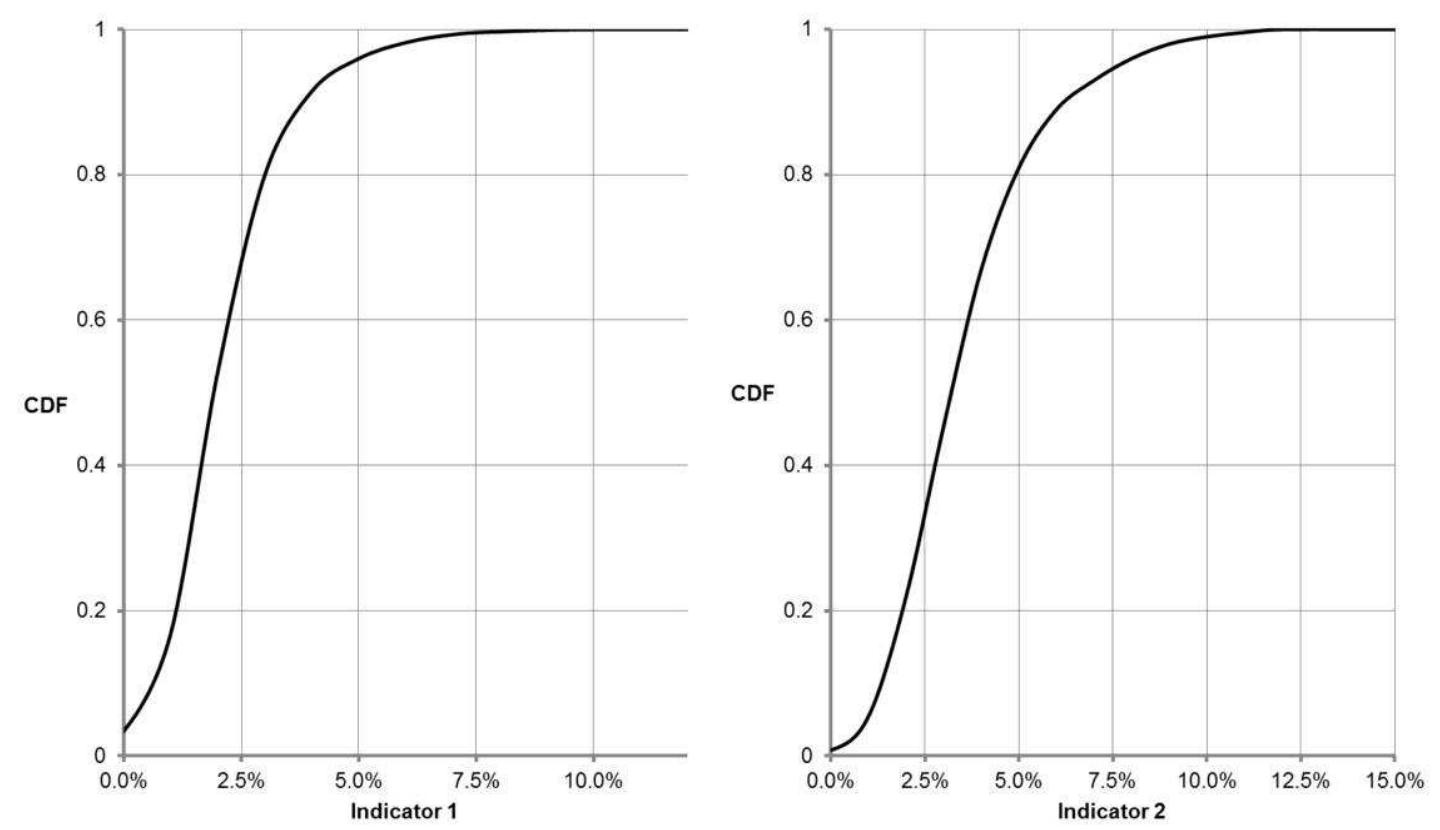

296

297 Figure 4 provides the cumulative probability distribution for the two different indicators considered.

${ }^{2}$ http://www.openturns.org/ 

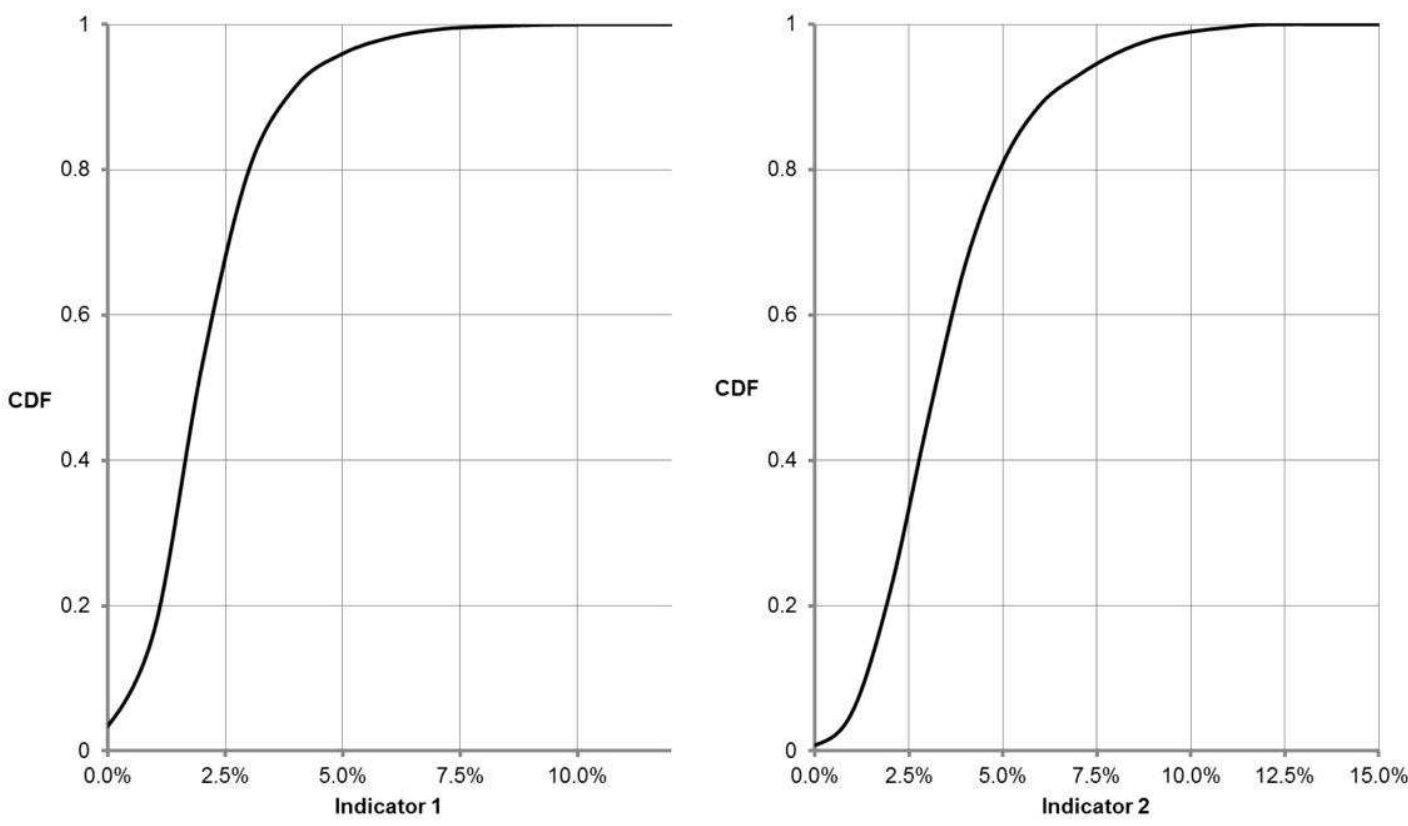

299

300

301

302

303

304

305

Figure 4: Uncertainty propagation results:Cumulative probability density function (CDF).On leftthe average relative overpressure due the $\mathrm{CO}_{2}$ injection within the 5 bars pressure footprint of the $\mathrm{CH}_{4}$ storage (indicator 1); on right the average relative overpressure due the $\mathrm{CO}_{2}$ injection within the 1 bar pressure footprint of the $\mathrm{CH}_{4}$ storage(indicator 2)

\subsubsection{Sensitivity analysis}

A global sensitivity analysis was performed on the three input parameters considered uncertain in the analysis (porosity, intrinsic permeability and compressibility) in order to determine which uncertainty has the greatest influence on the values of indicators. The analysis is based on the calculation of Sobol' indices, ${ }^{23}$ which were evaluated directlyusing the chaos coefficients from the metamodels. The sensitivity analysis outcomes for the two indicators are relatively similar: the porosity appears to be the most significant parameter for the pressure impact (normalized Sobol' indice of $50 \%$ for indicator 1 and $63 \%$ for indicator 2).For compressibility, the normalized Sobol'indices equal respectively $25 \%$ and $26 \%$, and for the permeability $12 \%$ and $4 \%$.This analysis is of first importance in a risk management perspective since diminishing the uncertainty level of the most important input parameters may change the overall risk level. In our specific case, if we consider that porosity and permeability are relatively well known, improving the probability distribution of the compressibility with for instance new measurements through laboratory or in situ 
measurements would certainly lead to a more specific probability distribution assessment and therefore to a moreprecise analysis of the risk level.

\subsection{Scenario 2: Native fluid migration through abandoned well}

321

322

323

\subsubsection{Presentation of the scenario and choices for the risks quantification}

This scenario focuses on the risk of brine leakage through an abandoned wellthat could potentially reach the Albian aquifer and impact its quality. According to the expert workshop held for the risks identification, several abandoned wells, close enough to the injection point and reaching the formation targeted for the $\mathrm{CO}_{2}$ injection, justify this analysis (see

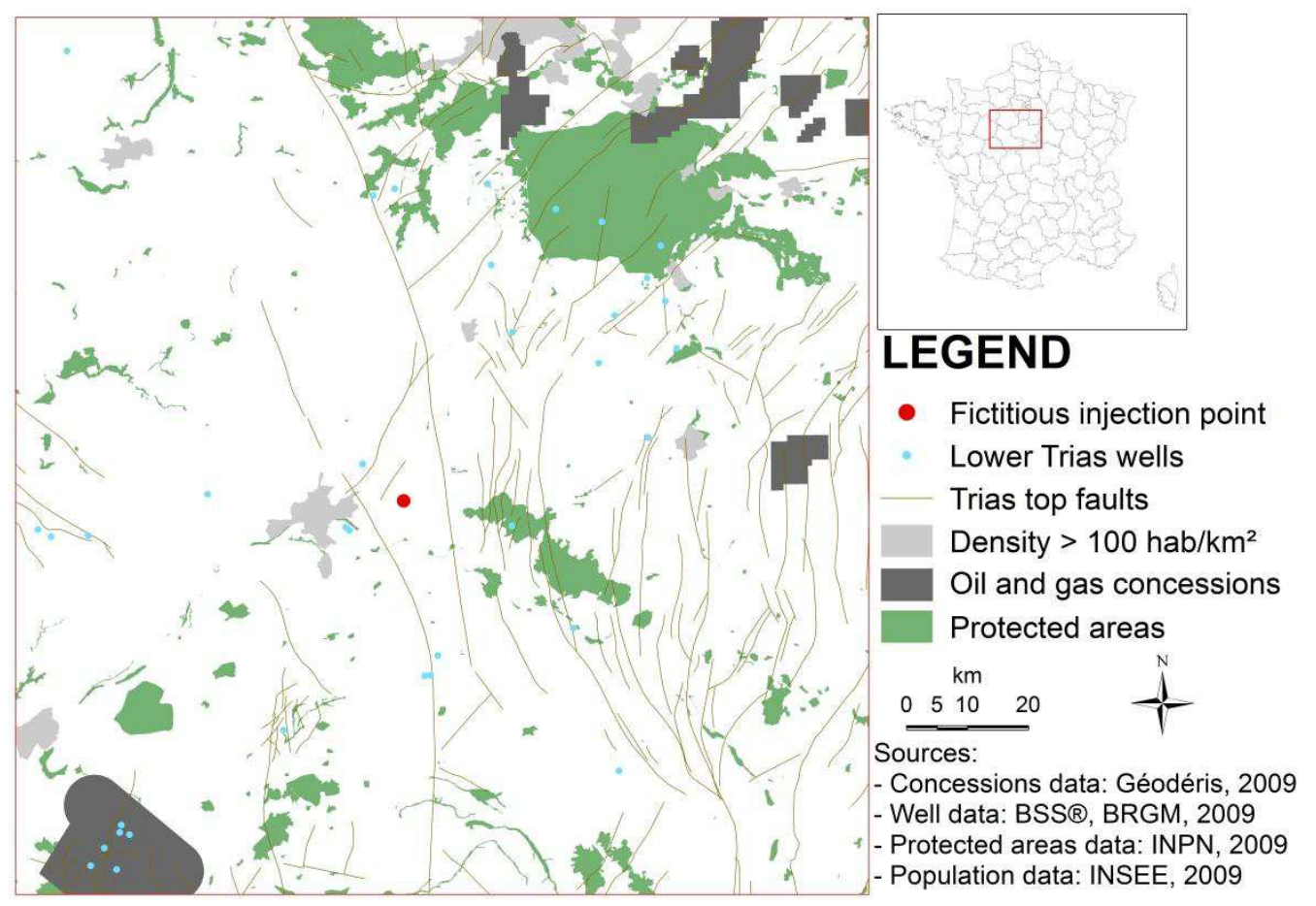

Figure 2). In the following, we present the analysis performed for the abandoned well the closest to the injection point (distance of ca. $10 \mathrm{~km}$ ). Because of the risk identification stage results, the possible existence of a non-mapped well during site characterization is not considered here.The risks are analysedduring the injection stage (30 years) and during 30 additional years after the end of the injection. 
A semi-analytical model (SAMBA) is used to quantify the potential brine migration that could occur through the abandoned well. ${ }^{24}$ This model has been developed to estimate saline brine intrusion due to an existing connection (e.g. abandoned well with poor integrity) between one deep saline aquifer over-pressurized by a $\mathrm{CO}_{2}$ injection and another overlying aquifer. The particularity of this model isto take into account the density difference between lifting and lifted brines during the migration. Despite its apparent simplicity, this model requires 25 different input parameters. ${ }^{24}$ This model enables the quantification of the leaking volume of brine, which has been chosen as indicator of the brine leakage impact for the analysis and evaluation of this scenario.

\subsubsection{Representation of available information}

As mentioned in the scenario 1 analysis section, the reservoir properties (porosity and permeability) can be represented by a probabilistic distribution function estimated with the characterized by high epistemic uncertainties. The available information, especially concerning the well integrity, is incomplete, imprecise or vague. In such cases, the knowledge of experts has been shown to be very useful to compensate the lack of observations. the mathematical form of the distribution (e.g., Gaussian, uniform, triangular, etc.), which is either theoretically known or (and it is the most usual case) supposedly chosen to best represent the available information. This expert knowledge elicitation was done for the compressibility in scenario 1 analysis. But, as outlined by Dubois and Prade, ${ }^{25}$ the probability may be too rich to be currently supplied by individuals as the identification of the probability distribution requires more information than what an expert is able to supply, which is often restricted to the 0.5 and 0.95 fractiles. Therefore, alternative formal frameworks to deal with 
epistemic uncertainties have been proposedinthe literature (see a review by Dubois and 358 Guyonnet ${ }^{26}$ ). In the present work and for this specific scenario, we propose to use the possibility representation of information (e.g., BaudritetDubois ${ }^{27}$ and references therein) and therefore represent with possibility distributions the input parameters with high epistemic uncertainties.

As

a

summary,
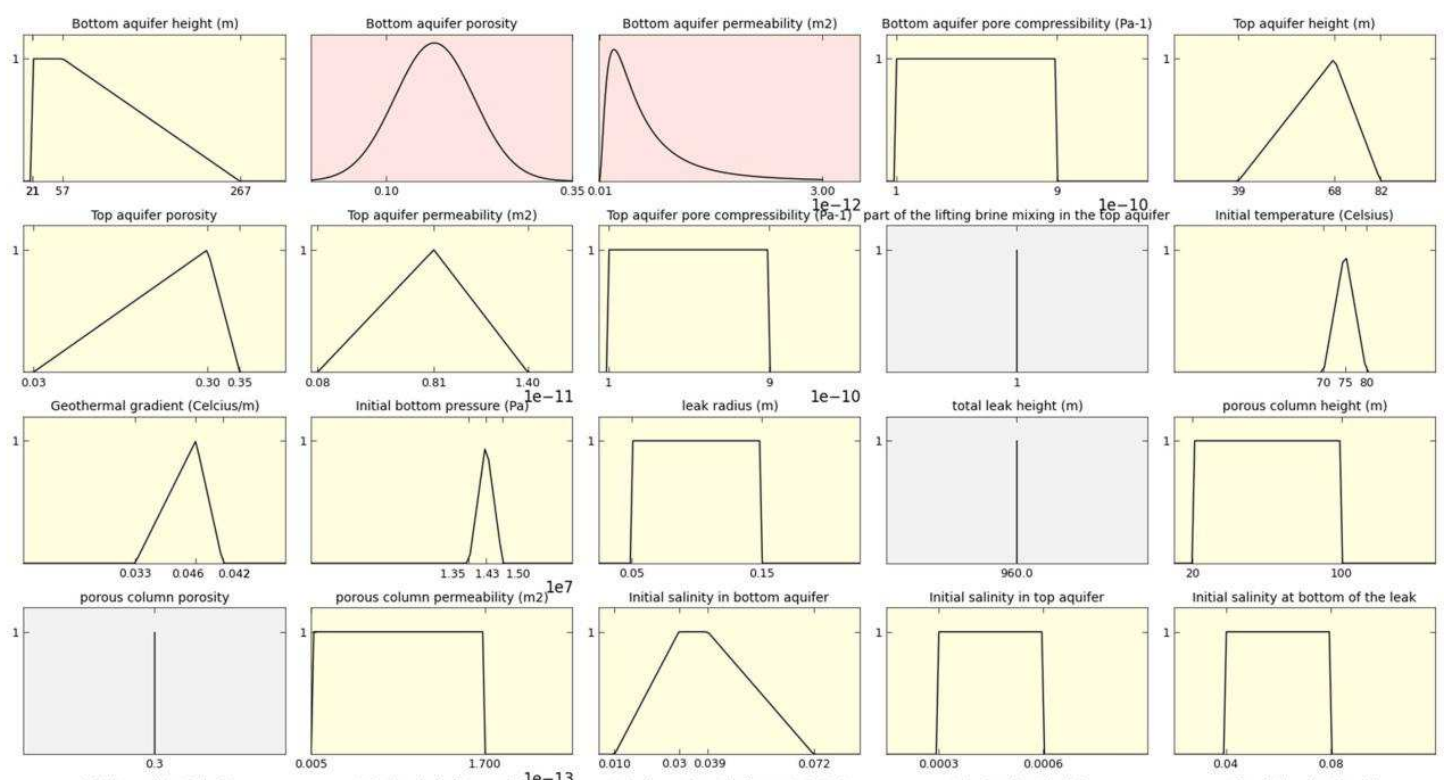

Initial salinity in top aquifer
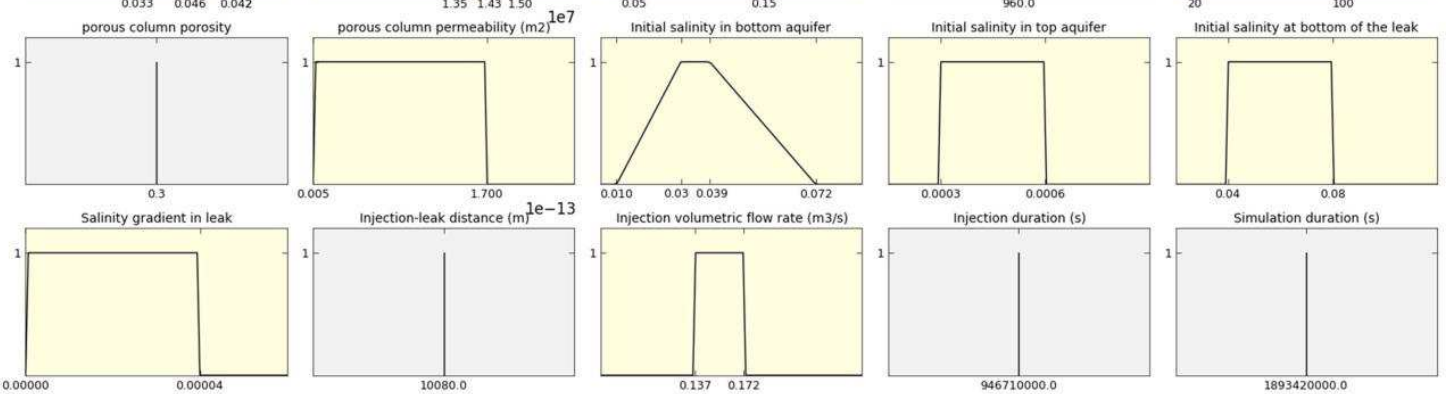

Figure 5 recalls the mode of representation chosen for the 25 input parameters needed for the

simulations ( 2 represented by probability distributions, 6 by fixed values, and 17 by possibility distributions). 

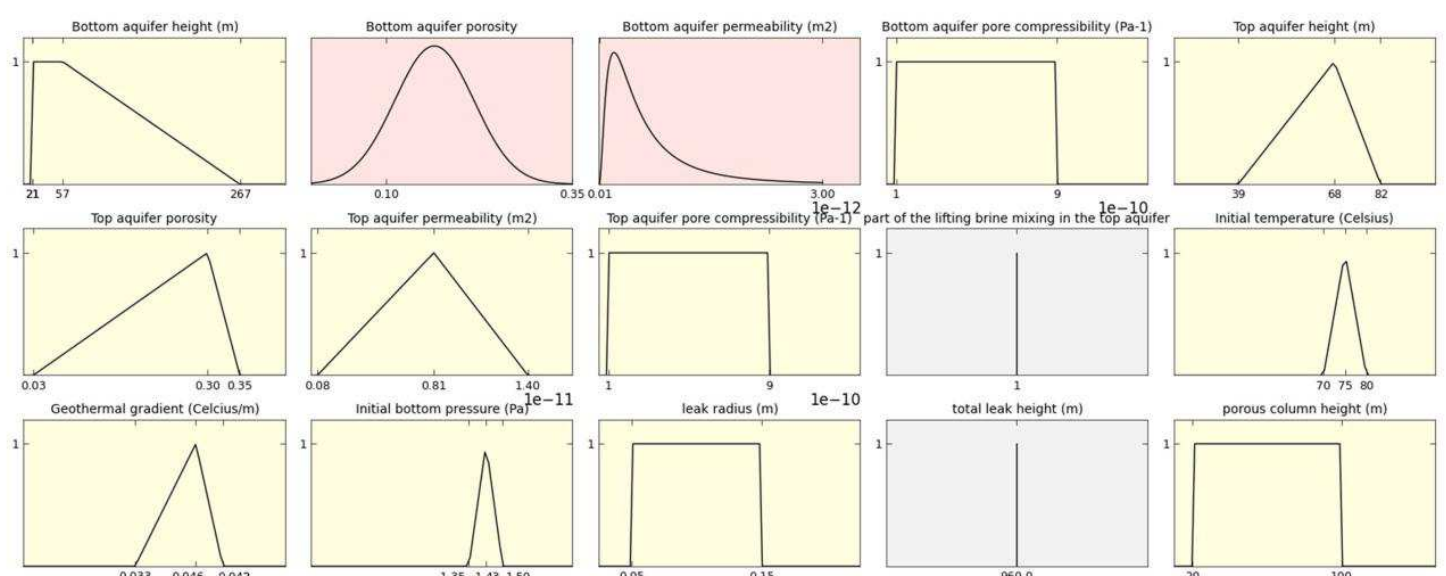

total leak height $(m$
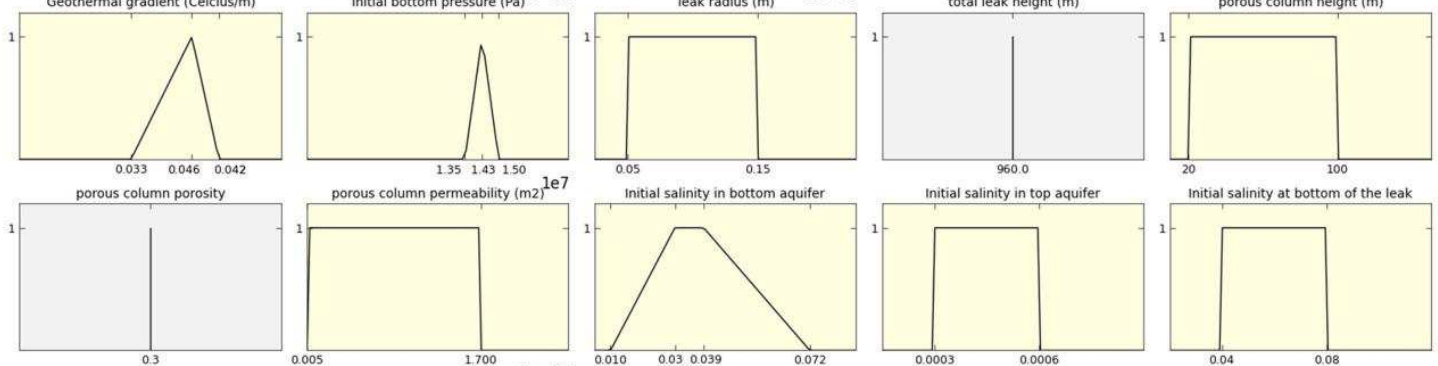

Initial salinity in top aquifer
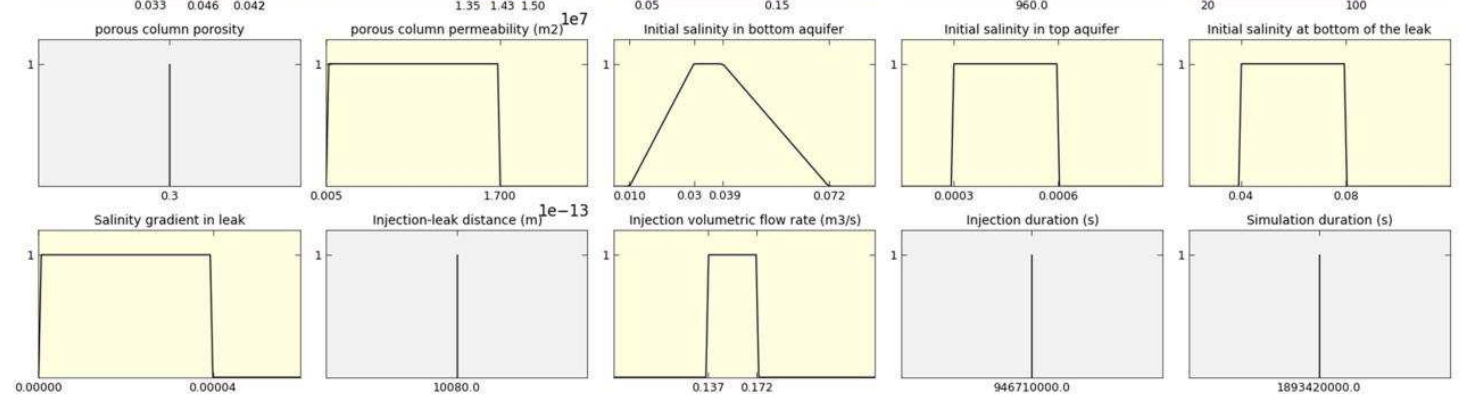

Figure 5 : Representation of information concerning the 25 parameters of the SAMBA model (grey: fixed value; yellow: possibility distribution; red: probability distribution) 
370 For propagating these possibility and probability representations through the model, we resort 371 to the independent Random Set propagation method. ${ }^{28}$ This framework enables to jointly 372 propagate possibility and probability distributions. It assumes independence between all 373 parameters and all sources of information. A convergence study showed that 3744,000 simulations is a good compromise between time computation (about 1 hour for 3754,000 simulations) and precision $( \pm 2 \%)$.In order to compare the results with a pure probabilistic treatment of the problem (as done for scenario 1 analysis), we performed the uncertainty propagation using Monte Carlo analysis based on probability distributions for all the input parameters (intervals were taken as uniform distributions).

The results of the uncertainty propagation step can be summarized, as proposed by Baudrit et al., ${ }^{28}$ within the formal framework of evidence theory in the form of two cumulative distribution functions (CDFs) bounding all the possible ones: a plausibility curve that corresponds to the situation for which the uncertainties drive to the most optimistic result; a belief function that corresponds on the contrary to the most unfavourable curve based on available data. The only known information concerning the true CDF is that it belongs to the 

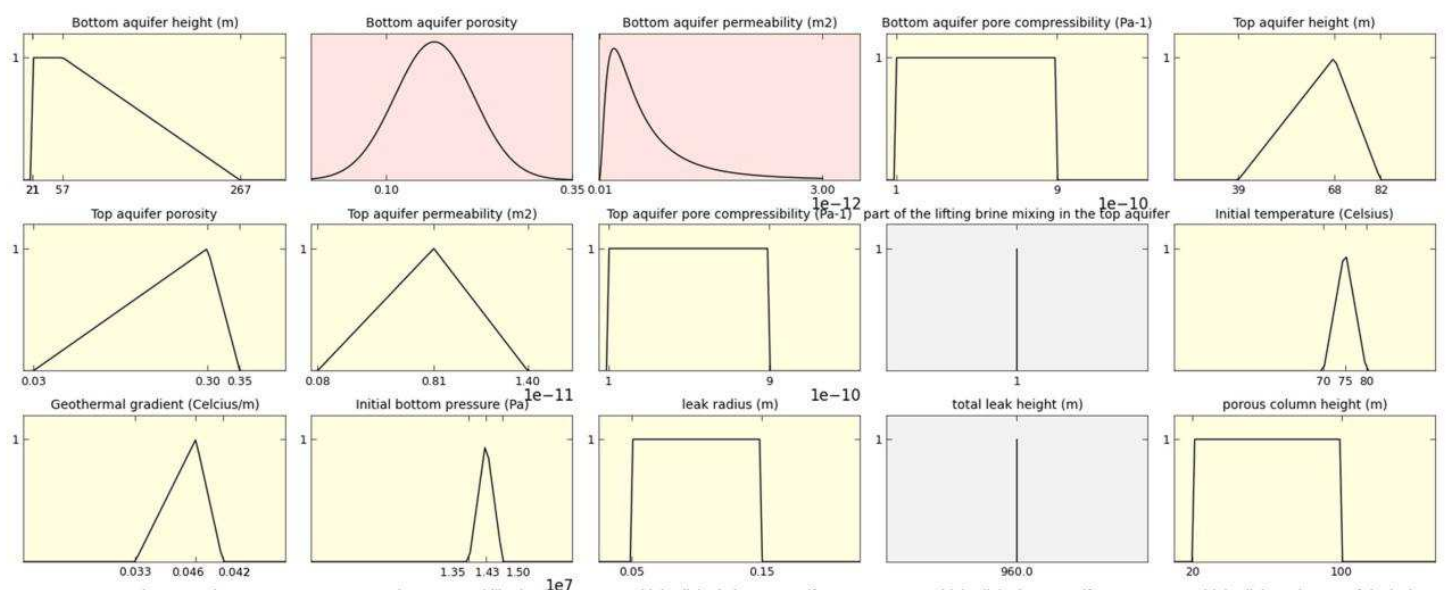

total leak height ( $m$
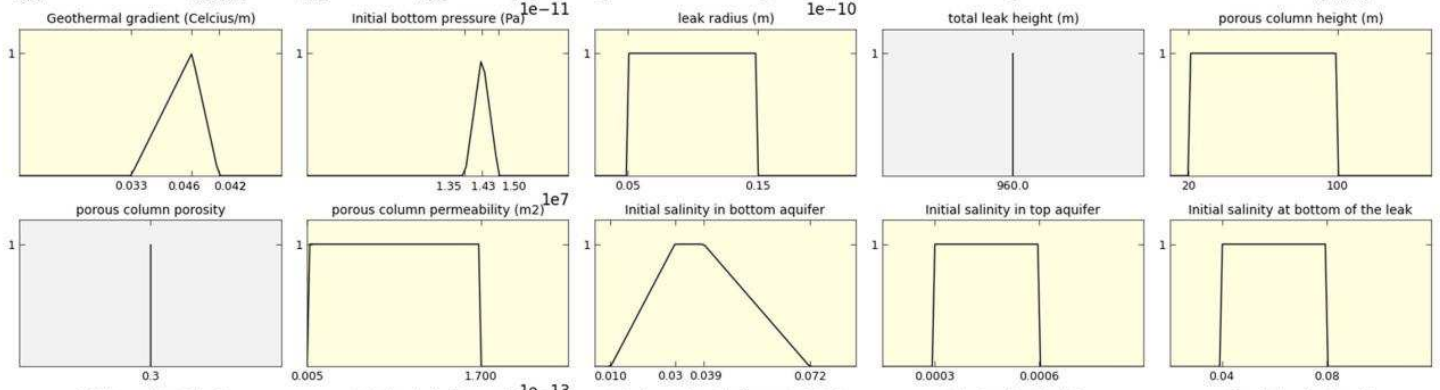

Salinity gradient in leak
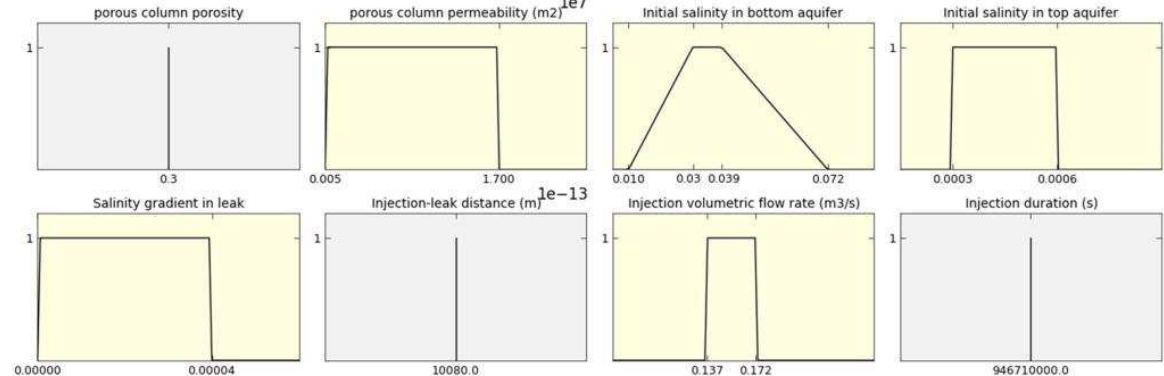

Injection duration (s)
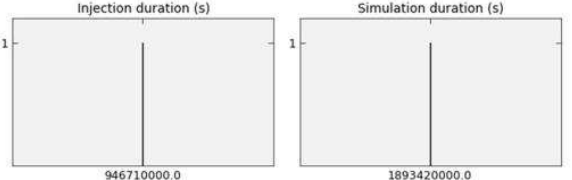

Figure 5that if the choice of assigning a uniform probability distribution to possible values

when confronted to ignorance is made (Monte Carlo approach), the results of simulations arebounded between both curves. However, Monte Carlo results give a false impression of confidence in the outcomes of propagation analysis by providing a unique probability value, but without enabling to quantify the effect of the lack of knowledge (epistemic uncertainty). 


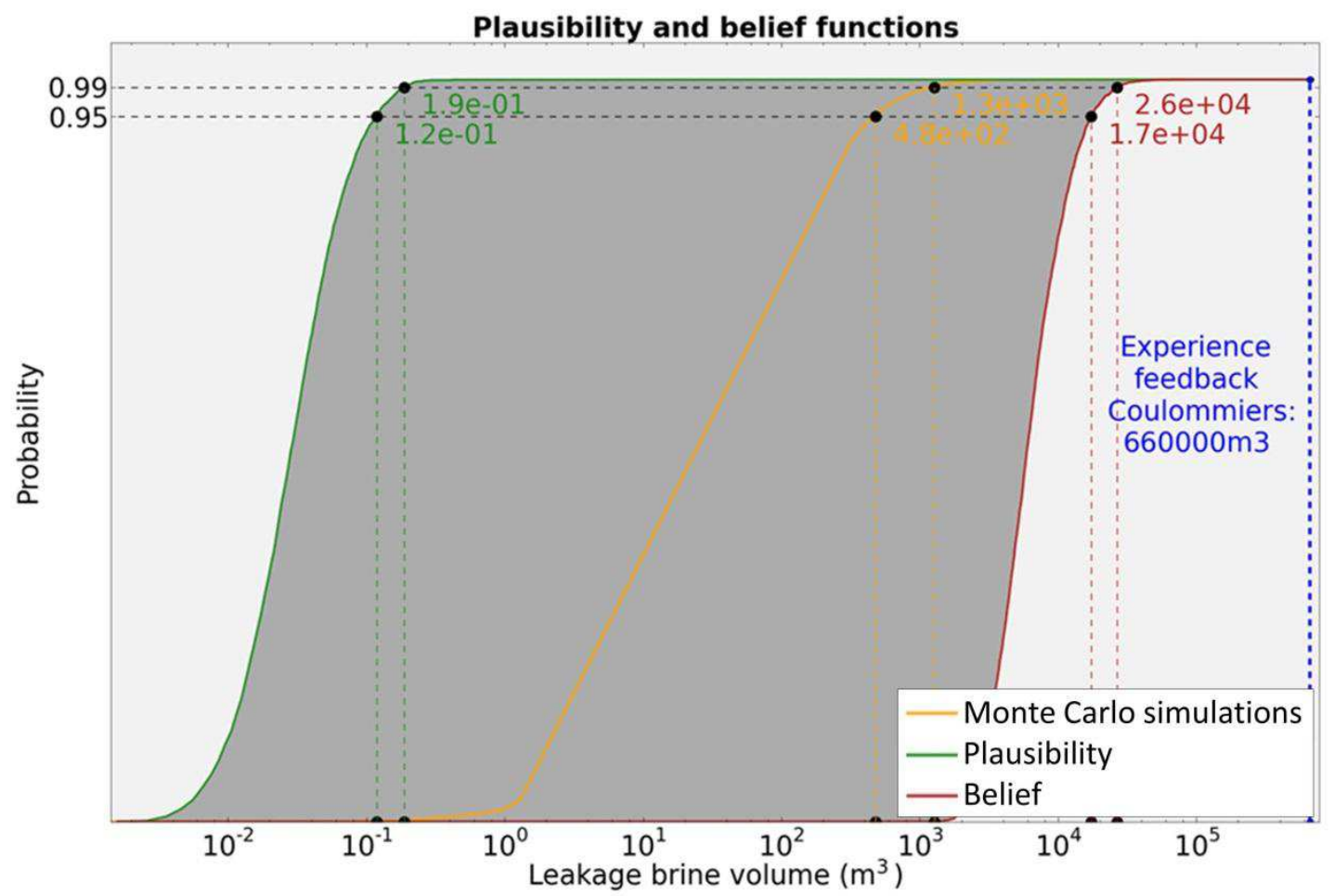

Figure 6 : Plausibility and belief functions obtained for the indicator brine leaking volume, and comparison with Monte Carlo simulations (the experience feedback indicated on this figure is detailed in section 5.2)

\subsubsection{Sensitivity analysis on uncertainties}

The uncertainty on the results can be estimated with the area between both curves, which is mainly dependent on epistemic uncertainty. It is thus possible to carry out a sensitivity analysis as in Ferson and Tucker. ${ }^{29}$ Instead of varying the investigated parameter as in anoneat-a-time sensitivity analysis, ${ }^{30}$ it consists in fixingthe investigated parameter to its reference value, while keeping the same representation mode for all the other parameters. The area between plausibility and belief obtained after fixinga parameter enables to quantify the uncertainty decrease that can be expected if data gathering gives evidence that this parameter is equal to its reference value with no uncertainty.

The result of this sensitivity analysis on the brine leakage scenario shows that the area decrease is more important for the following parameters: porous column permeability (91\%), porous column height $(60 \%)$, leak surface $(55 \%)$, bottom aquifer permeability $(25 \%)$. Note that these results should be interpreted cautiously since the area decrease depends on the 
reference value to which the parameter is fixed. The interest of such an analysis is to establish

409 priorities in data gathering: it is indeed not worth spending a lot of effort for acquiring data on 410 a parameter whose epistemic uncertainty has no real influence on results.

4115 Risk evaluation

412 As recalled in the introductory section, the risk evaluation consists in comparing the risk 413 analysis results against the acceptability targets. Risk criteria should theoretically be defined 414 beforehand and recalled in the establishment of the context. In this paper they are discussed in 415 this section on risk evaluation for clarity purposes. It is important to note that no standardized 416 criteria are currently available for $\mathrm{CO}_{2}$ storage risks specifically. ${ }^{31}$ In practice, risk criteria may 417 be set in order to respect the environmental regulations in place but also according to other 418 stakeholders expectations and demands (e.g. other users of a similar geologic formation, local 419 population).In this paper, the storage site is fictitious and thus, the stakeholders concerns cannot be discussed and accounted for. Therefore, in the following subsections, rather than 421 discussing the acceptability of the two risks scenarios, we discuss how the results of the risk analysis could be used in a real situation in order to enable a fully informed decision-making. 

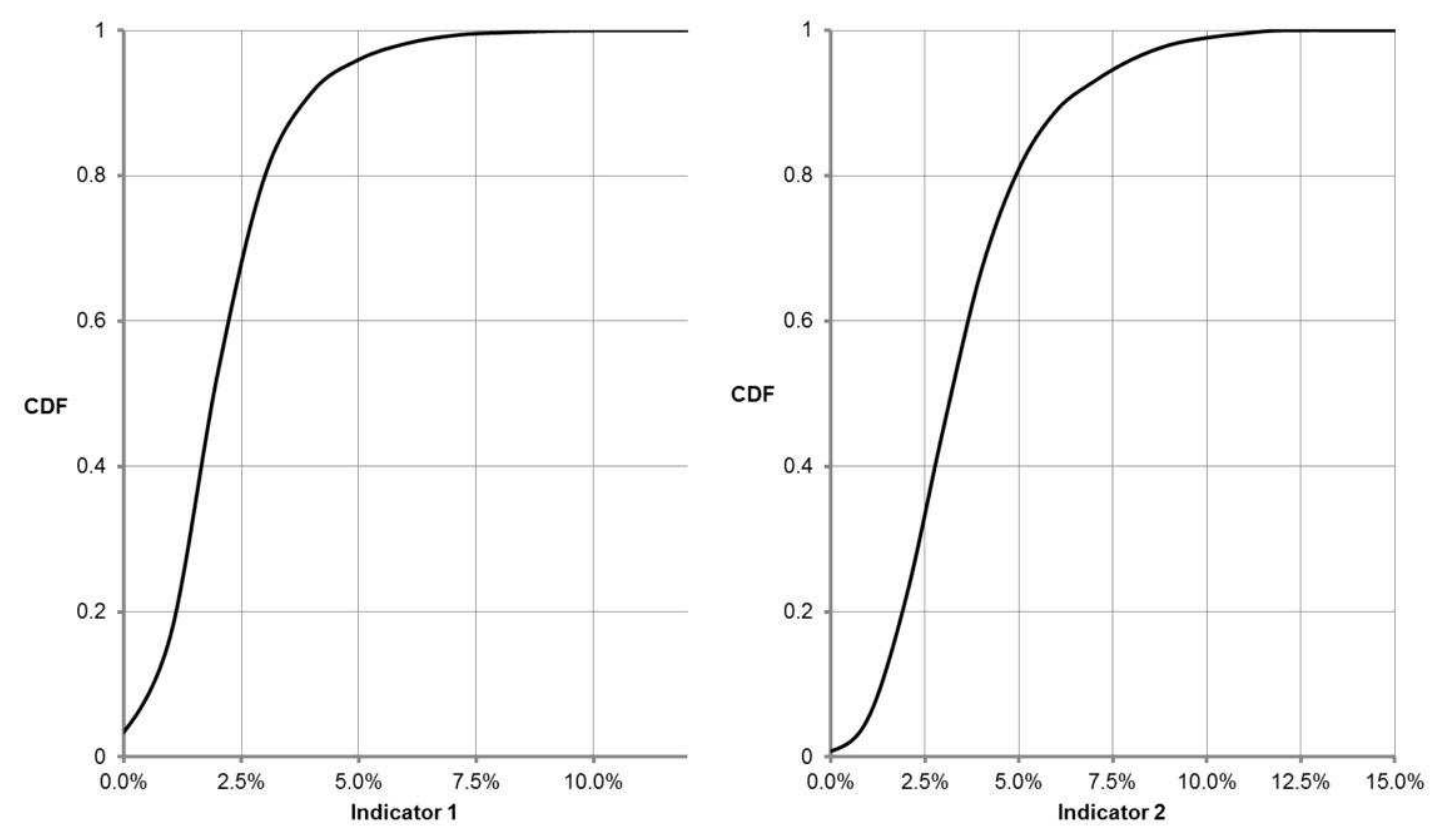

Figure 4, the distributions of the two indicators are different and the pressure impact is higher in the 1 bar footprint of the $\mathrm{CH}_{4}$ storage than in the 5 bars footprint. This is explained, in our case, by the fact that the 1 bar footprint of the natural gas storage goes very close to the $\mathrm{CO}_{2}$ storage injection. The 5 bars footprint therefore gives more localized information of the overpressure at the gas storage siteand in that sense appeared to be the best indicator to assess the local disruption at the $\mathrm{CH}_{4}$ storage site.However, establishing one criterion relatively to this indicator to evaluate the acceptability of this perturbation is difficult because it is strongly dependent on the vulnerability of the gas storage to pressure changes. The risk criterion is likely to be defined after discussions between the different users of the geological formation and the regulators. If, after assessment, an impact in pressure until $\mathrm{X} \%$ is found unable to compromise the natural gas storage operations (due for example to the safety margins in these operations), the stakeholders may for instance establish the following risk criterion: the risk 
generated by the $\mathrm{CO}_{2}$ storage operationsis considered acceptable if thereis at least a $99 \%$ confidence level that the pressure impact in the 5 bars $\mathrm{CH}_{4}$ storage footprint is lower than $\mathrm{X} \%$. The treatment of this risk scenario should be decided with respect to that criterion. For the sake of illustration in our study, let us arbitrarily consider a value $X=5 \%$ (without any consideration of the relevance of this value). The associated level of confidence is $96 \%$, meaning that the risk level would be close to acceptability(see on

445
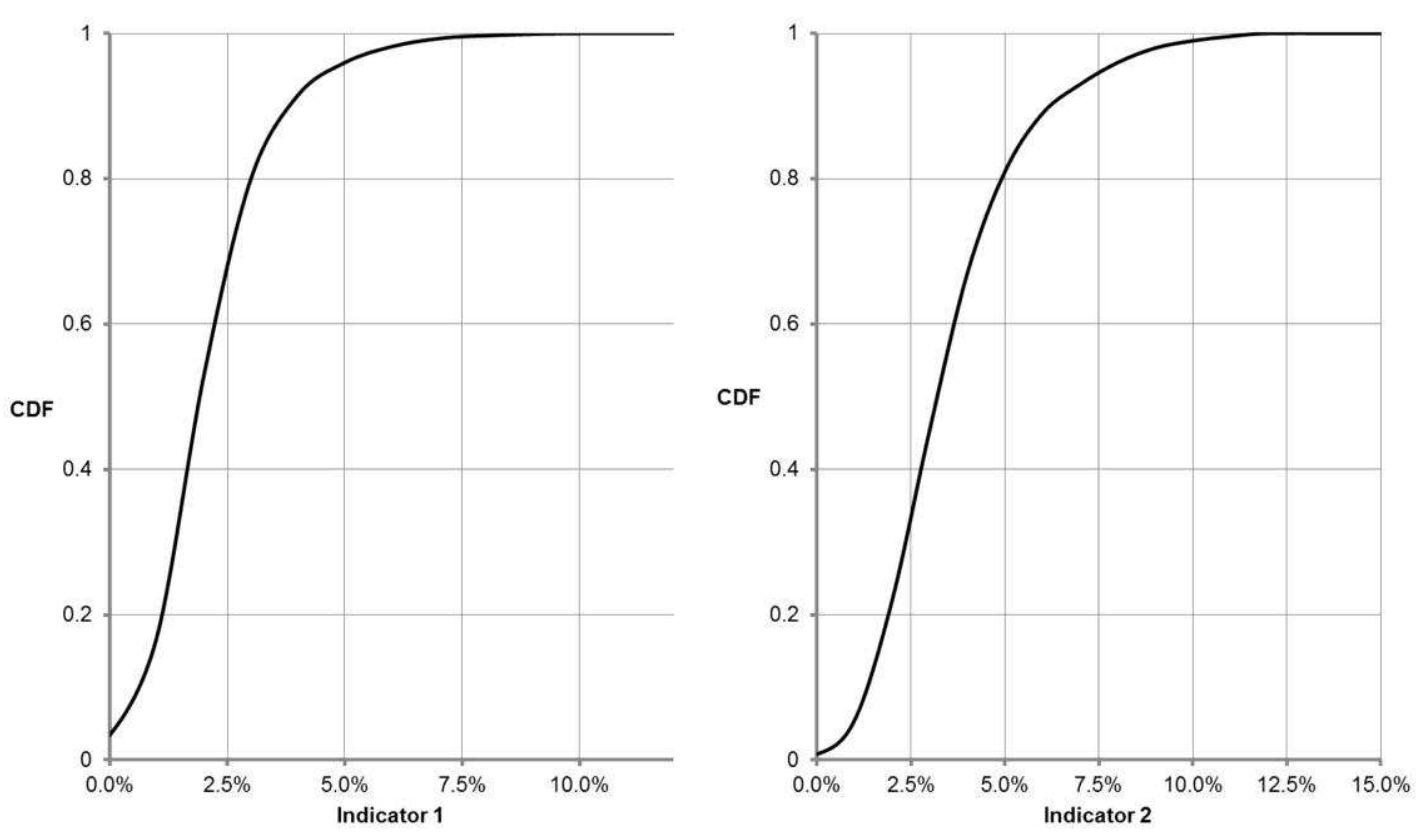

Figure 4). In such a case, the decided risk treatment might be the performance of another analysis to quantify the pressure impacts with more precision (through for instance model improvement). An additional characterization of the poorly known but influential input parameters (outcomes of the global uncertainty analysis) wouldbe another way to reduce the uncertainties on the risk level. Alternatively, with $X=1 \%$ the project wouldnot be acceptable and itwouldbe necessary to lower the level of risk rather by modifying the injection pattern and/or setting mitigation measures. 


\subsection{Scenario 2: Native fluid migration through abandoned well}

454

Similarly to the former scenario, no firm regulatory criterion has been found regarding the volume of brine leakage. Instead, an experience feedback study of brine leakage in the Paris Basin wascarried out in order to define acceptabilitythresholds.To our knowledge, the only reference isa brine leakage from a geothermal well(high salinity) near Coulommiersin the Paris Basin. ${ }^{32} \mathrm{~A}$ leakage of $660,000 \mathrm{~m}^{3}$ is reported, with no significant incidence on drinking water supplies. The context of this leakage is obviously likely to be different than the one of ourstudy and therefore the comparison with this value should be cautious. In a conservative approach, let us assume that the situation may beconsidered acceptable if there is at least $99 \%$ confidence that the leakage volume is lower than the experience feedback value.As shown onFigure 6, the most unfavourable leakage value is more than two orders of magnitude lower thanthe chosen experience feedback. Thus, the situation would be considered acceptable with the considered criterion.The results obtained with Monte Carlo simulations would give the same evaluation outcomes. However,the possibilistic treatment of uncertainties nuances the Monte-Carlo results, by clearly indicating the level of epistemic uncertainties. Using a different risk criterion (brine volume comprised between 1300 and $26000 \mathrm{~m}^{3}$ with a degree of confidence of $99 \%$ ), the Monte-Carlo-based approach would have directly led to a decision (acceptability), while the possibility approach would have suggested to make additional studies or take additional safeguards, as it does not exclude a leakage volume in excess of the evaluation criterion.This highlights the importance of choices in the mathematical tools for representing the lack of knowledge especially in the early phases of the $\mathrm{CO}_{2}$ storage project, where few data is available. 


\section{Summary and Conclusions}

In the present paper, we describe a new approach for performing a quantitative risk assessment of $\mathrm{CO}_{2}$ geological storage operations. Compared to existing methodologies in the $\mathrm{CO}_{2}$ geological storage domain that are mostly qualitative or semi-quantitative, our approach has been designed in order to provide quantitative elements to evaluate the risks acceptability. This approach is based on the international standards regarding risk management practices, which are applied to the subsurface and to $\mathrm{CO}_{2}$ geological storage operations. Our approach is presented on a case study, conceived to be representative of the level of information available at an early stage of a project. The application of the different steps of the methodology shows how the challenges linked with $\mathrm{CO}_{2}$ storage risks assessment could be faced: in particular, our approach proposes a detailed assessment and representation of the partial knowledge of the geological medium in terms of intrinsic properties and processes. The complexity and number of processes and mechanisms impose a strong effort of risk identification combininggeneric risk database and experts knowledge in numerous domains in order to come up with representative risk scenarios to be analysed. A quantitative analysis of these scenarios is relevant only if it is accompanied by a comprehensive uncertainties management framework including data collection and description, uncertainty representation and propagation. In this study the analysis has been performed using different kinds of modelling tools associated with different ways of dealing with uncertainties, which highlights the importance of a proper combination between risk quantification and uncertainty management tools. The risk evaluation stage has been carried out by assuming risk acceptability criteria, but in real-case application, this wouldrequire a deeper joint analysis between stakeholders (operators, regulators).

In the end, it has been shown that the proposed approach can lead to the risk scenarios selection and quantification in a transparent way, i.e. without introducing subjectivity prior to 
500 the risks acceptability evaluation. The implemented approach also appears to be flexible to 501 different tools and contexts regarding the available data. The results of this approach could 502 therefore be used, in different situations, as a scientific basis for discussion between 503 stakeholders for decision-making and as arguments for prioritizing additional characterization 504 and quantification (modelling), if required. In addition, the results constitute important 505 information for achieving the next stages of the risk management process, including the set-up 506 of risk monitoring or treatment measures. Such quantitative approach could also help in the 507 risk communication as it gives a clear picture of the risk related to $\mathrm{CO}_{2}$ storage project with 508 the associated uncertainties, thus contributing to the confidence and acceptance of a project. 


\section{Acknowledgments}

511 This work was carried out in the framework of the project MANAUS1 and MANAUS2, funded

512 by French Environment and Energy Management Agency (ADEME)(contracts N1094C0003

513 and $\mathrm{N}^{\circ}$ 1094C0087). The authors are grateful to their partners atGEOGREEN, INERIS and

514 OXAND for their involvement in the expert workshops. The authors greatly appreciated the

515 comments from Yann Le Gallo(from GEOGREEN) that helped to improve the paper.

516 


\section{References}

1. IPPC.IPPC Special Report on Carbon Dioxide Capture and Storage.Cambridge University Press, Cambridge, United Kingdom and New York, NY, USA, 442 p.(2005).

2. EC, 2009. Directive 2009/31/EC of the European Parliament and of the Council of 23 April 2009 on the geological storage of carbon dioxide and amending Council Directive 85/337/EC, European Parliament and Council Directives 2000/60/EC, 2001/80/EC, 2004/35/EC, 2006/12/EC, 2008/1/EC andRegulation (EC) No. 1013/2006.

3. ISO 2009a. ISO 31000:2009. Risk Management - Principles and guidelines.International Standard Organisation.

4. Bouc O., Bellenfant G., Dubois D., Guyonnet D., Rohmer J., Gastine M., Wertz F., Fabri H. Geological Storage Safety Assessment: Methodological Developments. PSAM 10 - 10th International Probabilistic Safety Assessment \& Management Conference. Seattle, United States (2010).

5. Koornneef J, Ramírez A, Turkenburg W, Faaij a. 2012. The environmental impact and risk assessment of $\mathrm{CO} 2$ capture, transport and storage. An evaluation of the knowledge base.Progress in Energy and Combustion Science38 62-86, (2012)

6. Bowden A.a, Pershke D, Chalaturnyk R. Geosphere risk assessment conducted for the IEAGHG Weyburn-Midale CO2 Monitoring and Storage Project.

International Journal of Greenhouse Gas Control.16.276-290. (2013). 
7. Oldenburg, C.M., Bryant, S.L., Nicot, J.P. Certification framework based on effective trapping for geologic carbon sequestration. Int. J. Greenhouse Gas Control, 3 (4), pp. 444457, (2009).

8. Wildenborg, T., Leijne, T., Kreft, E., Nepveu, M., Obdan, A., Wipfler, L., van der Grift, B., Hofstee, C., van Kesteren, W., Gaus, I., Czernichowski-Lauriol, I., Torfs, P., Wojcik, R., Orlic, B. 2005. Risk Assessment methodology for CO2 Storage: The scenario approach. In: Thomas, D.C., Benson, S.M. (eds), The CO2 Capture and storage Project (CCP), II, pp. 1283-1305 (2005).

9. Pawar, R.; Bromhal, G.; Dilmore, R.; Foxall, B.; Jones, E.; Oldenburg, C.; Stauffer, P.; Unwin, S.; Guthrie, G. Quantification of Risk Profiles for Atmospheres and Groundwater; NRAP-TRS-III-003-2013; NRAP Technical Report Series; U.S. Department of Energy, National Energy Technology Laboratory: Morgantown, WV,p 28.(2013).

10. ISO 2009b. ISO 31010:2009. Risk management - Risk assessment techniques.International Standard Organisation.

11. Chapuis F., Bauer H., Grataloup S., Leynet A., Bourgine B., Castagnac C., Fillacier S., Lecomte A., Le Gallo Y., Bonijoly D., Lecomte A., Y. 2011. Geological investigations for $\mathrm{CO} 2$ storage: from seismic and well data to 3D modeling. GHGT-10.Energy Procedia4 4591-4598(2011).

12. Bonijoly, D. with the collaboration of J. Barbier, J.M. Matray, C. Robelin, C. Kervevan, D. Thierry, A. Menjoz, C. Coticheand B. Herbrich., 2003. Feasibility of CO2 storage in 
569

570

571

572

573

574

575

576

577

578

579

580

581

582

583

584

585

586

587

588

geothermal reservoirs.Example of the Paris Basin, France.BRGM-CFG-ANTEA contribution to the GESTCO project.Fifth RTD Framework Programme Report BRGM/RP-52349-FR. (2003) 135pp. www.brgm.fr.In french.

13. Lopez S., Hamm V., Le Brun M., Schaper L., Boissier F., Cotiche C., Giuglaris E. 2010. 40 years of Dogger aquifer management in Ile-de-France, Paris Basin, France. Geothermics39 : 339-356 (2010).

14. Bouc O., Réveillère A., Ducellier A., Manceau J-C,.Projet CPER Artenay - Sélection d'un site pour le stockage géologique de $\mathrm{CO} 2$ et étude des principaux risques associés. Rapport BRGM/RP-59534-FR.In French.(2011)

15. Humez P., Audigane P. Lions J.· Chiaberge C. Bellenfant G. Modeling of CO2 Leakage up Through an Abandoned Well from Deep Saline Aquifer to Shallow Fresh Groundwaters. Transp Porous Med 90:153-181(2011).

16. Grataloup S, Bonijoly D, Brosse E, Dreux R, Garcia D, Hasanov V, Lescanne M, Renoux P, Thoraval A. A site selection methodology for $\mathrm{CO} 2$ underground storage in deep saline aquifers: case of the Paris Basin. Energy Procedia1,2929-2936.(2009)

17. Bowden A., Rigg A. 2004. Assessing risk in CO2 storage projects, APPEA Journal, 44: 677-702(2004). 
18. Bouc O., Audigane P., Bellenfant G., Fabriol H., Gastine M., Rohmer J., Seyedi D. GHGT-9 Determining safety criteria for CO2 geological storage. EnergyProcedia1 : 24392446 (2009).

19. Bouc O., Fabriol H., Brosse E., Kalaydjian F., Farret R., Gombert Ph., Berest P., Lagneau V., Pereira JM., Fen-Chong T. - Lignes de conduite pour la sécurité d'un site de stockage géologique de CO2. BRGM/RP-60369-FR, 154 p., 3 annexes.In French(2011).

20. Pruess, K., Oldenburg, C.M., Moridis, G.J., 1999. TOUGH2 User's Guide, Version 2.0.

21. Oldenburg CM, Moridis G. J., Spycher N., Pruess K. (2004) - EOS7C Version 1.0: TOUGH2 Module for Carbon Dioxide or Nitrogen in Natural Gas (Methane) Reservoirs. LBNL-56589.

22. Sudret, B.,.Uncertainty propagation and sensitivity analysis in mechanical models Contributions to structural reliability and stochastic spectral methods.Habilitation à diriger des recherches, Université Blaise Pascal, Clermont-Ferrand (252 pages) (2007).

23.

Saltelli,A.,Ratto,M.,Andres,T.,Campolongo,F.,Cariboni,J.,Gatelli,D.,Saisana,M.,Tarantola, S.,Global SensitivityAnalysis: The Primer. Wiley, Chichester, UK 304pp.(2008)

24. Réveillère, A., 2013. Semi-analytical Solution for Brine Leakage Through Passive Abandoned Wells Taking Account of Brine Density Differences. Transport in Porous Media, 100,337-361, (2013). 
615

616

617

618

619

620

621

622

623

624

625

626

627

628

629

630

631

632

633

634

635

25. Dubois D, Prade H. Possibility theory and data fusion in poorly informed environments, Control Engineering Practice, 2(5), 811-823 (1994).

26. Dubois, D. and Guyonnet, D. 'Risk-informed decision-making in the presence of epistemic uncertainty', International Journal of General Systems, 40 (2), 145-167(2011).

27. Baudrit, C. and Dubois, D., Practical representations of incomplete probabilistic knowledge. Computational statistics \& data analysis, 51, 86-108(2006).

28. Baudrit, C., Guyonnet, D., Dubois, D., Joint propagation of variability and imprecision in assessing the risk of groundwater contamination, Journal of Contaminant Hydrology 93, 7284(2007).

29.Ferson S., Tucker W.T., 2006. Sensitivity analysis using probability bounding, Reliability Engineering \& System Safety,91 (10-11), 1435-1442.(2006)

30. Campolongo, F., Kleijnen, J., Andres, T., Screening methods. In: Saltelli, A., Chan., K., Scott, M. (Eds.), Sensitivity Analysis. John Wiley and Sons Publishers, New York, pp. 65-89. (2000)

31. Koornneef, J., Ramirez, A., Turkenburg, W., Faaij, A. The environmental impact and risk assessment of $\mathrm{CO} 2$ capture, transport and storage -an evaluation of the knowledge base using the DPSIR framework. EnergyProcedia, 4, 2293-2300 (2011). 
636 32. Vernoux J.F. Etude bibliographique sur le suivi des risques engendrés par les forages 637 profonds sur les nappes d'eau souterraine du bassin Seine-Normandie. Technical report (in 638 french). BRGM/RP-51312-FR. (2002).

639

640 33. Martin J.C. 2009. Projet CPER Artenay - Etude du site d'Artenay - Caractéristiques 641 hydrodynamiques des réservoirs du Dogger et du Trias. Rapport BRGM/RP-57119-FR.In 642 French.

643

644 34. Dai, Z., Stauffer, P. H., Carey, J. W., Middleton, R. S., Lu, Z., Jacobs,. Spangle, J. F., 645 L, Hnottavange-Telleen, K., Pre-site characterization risk analysis for commercial-scale 646 carbon sequestration, Environmental Science \& Technology, 48, 3908-3915(2014).

647 